\title{
Food Hubs and Rebuilding Missing Middle Market Structure in Agriculture: The Social in Supply Chain Development
}

\section{Stephen Luoni}

SUSTAINABILITY

\section{ABSTRACT - Tens of millions of Americans became food insecure during} the COVID-19 pandemic as independent farmers dumped millions of tons of food due to economic lockdowns. Yet contract growers looped into vertically integrated monopoly supply chains escaped system breakdowns. Food provisioning is often seen as polarized between local scale and continental/ global market scale. Food supply and consumption are functions more of market structure than scale. Farmers reliant on direct sales to local restaurants, schools, universities, and hospitals saw their markets evaporate overnight. This Food Away from Home market constitutes 54 percent of food consumed nationally yet is vulnerable since direct-to-consumer sales lack supply chain structure. Urban food hubs dotting American cities before their eclipse by agrifood monopolies could have maintained supply. The food hub was a resilient public supply channel (a food commons) organizing a plurality of local and global providers alike. To address food insecurity our food planning effort for the State of Hawaii is premised on building similar missing middle market structure featuring a food hub, a food innovation center, and farm base yard processing facilities.

Keywords: food hubs, infrastructure, middle market structure, public good, supply chain

As Carolyn Steel posited, "we have never seen food's true potential, because it is too big to see. But viewed laterally, it emerges as something with phenomenal power to transform not just landscapes, but political structures, public spaces, social relationships, cities. Its effects depend on those who control it." 1 
By April 2020, tens of millions of Americans suddenly became food insecure, adding to the 14 percent of American households already experiencing food insecurity before the COVID-19 pandemic. Meanwhile, independent farmers dumped millions of tons of food due to economic lockdowns, while contract growers looped into vertically integrated supply chains of agrifood monopolies escaped system breakdowns. ${ }^{2}$ Farmers reliant on direct sales, mostly small independents supplying local restaurants, schools, universities, and hospitals, saw their markets evaporate overnight. Surprisingly, this Food Away from Home (FAFH) market constitutes 54 percent of food consumed nationally ${ }^{3}$ yet is vulnerable to disruption since direct-to-consumer sales lack supply chain structure. Urban food hubs or food districts that once dotted American cities before their reconfiguration by monopoly market structure in the twentieth century could have readily maintained food supply to consumers, avoiding wastage, hunger, and the systematic wealth destruction now occurring among small and mid-sized farmers.

Middle agricultural infrastructure connecting independent farmers to local food processors, distributors, and retailers aggregated in city centers was the backbone of community food supply before its eclipse by a junk-food industrial complex. As this industrial food complex shows signs of faltering from its own negative externalities and unsustainability, short food supply chains are reemerging through grassroots initiatives. This includes our food planning work with the State of Hawaii to re-localize aspects of its food system through island-wide supply chain planning including the design of a food hub, a university-based food innovation center, and base yard microprocessing centers for remote farms. Through systems thinking, architects have a role in helping communities re-envision their food systems by providing operational framework programming, policy construction through design thinking, resource value chain mapping, and urban and architectural design. Design professionals' problem-solving skills can be expanded to address logistical expressions of space across a resource chain like food to ensure resiliency (the sustained functioning of a system even when disrupted). The goal is to create healthier and more resilient cities, both important public goods.

\section{THE RETREAT OF MIDDLE MARKET STRUCTURE}

Like other highly capitalized market sectors in America now dominated by monopolistic structure (technology, durable goods, financing, and retail, for instance) food provisioning has become polarized between local and continental/global market scales. In their seminal essay: "Why Worry about the Agriculture of the Middle?," Fred Kirschenmann and colleagues contend that food supply and consumer patterns are functions of "market structure" more than that of scale. Farms of any size can conceivably participate anywhere on the market spectrum between direct-to-consumer sales (e.g., farmers markets, CSAs, restaurants) and vertically integrated 
commodity chains culminating at large grocers like Walmart, Whole Foods Market, Costco, and Kroger. ${ }^{4}$ Though small- and mid-sized farmers lack the logistical capacities to guarantee shelf-stable product flow, quantity, and uniformity required in monopoly supply chains, many mid-sized farmers are too large for the direct sales market. While farm-to-table sales typically offer more diversified, nutritious, and fresh products, these relationships lack the "supply chain redundancy" characteristic of resilient market structure. Lack of a supportive market structure adds to the chronic uncertainties that plague farming, which will only worsen with climate change. The average age of the American farmer is fifty-eight ${ }^{5}$ as the industry is simply not reproducing the next generation of farmers.

Middle market structure, or short supply chains, encompassed regional exchange between direct sales (no supply chain) and monopoly supply chains. This now missing middle sector was centralized in cities and once the mainstay for independent farmers, transporters, wholesalers, middlemen, processors, and retailers. Food's middle market structure was a public sphere where issues over food sovereignty about how and what to eat were socially constructed traditions in regional "food commons" across the nation. Their pluralistic market structure constituted a web of social and economic exchanges equally supportive of small and large actors alike. Agrifood's eventual privatization of food logistics absorbed middle market structure into what became continental-scaled black boxes. For now, agrifood's global supply chains offer the greatest food provisioning security, efficiency, access (due to low prices), abundance, and product variety. Despite delivering what food author Michael Pollan calls "food-like substances" derived from sugar, salt, corn, soybean, wheat, and industrial meat, America's industrial food complex is unparalleled in its calorie production and capacity to help feed the world.

\section{The City as a Market}

Yet, as Kirschenmann argues, "enterprises of the middle have traditionally constituted the heart of U.S. agriculture" ${ }^{6}$ and still shape much of our lingering imagery and literacy about food. Before WWII, regional foodsheds triangulated connections among local farms, continental imports, and downtown wholesale markets, resulting in a middle market structure. Middle agriculture infrastructure included logistical support distributed across rural landscapes in independent granaries, storage facilities, and livestock auction arenas. Cold chain transport by rail, wagon, steamships in river cities, and eventually truck, delivered local and faraway rural produce to networks of food processors, abattoirs, packagers, distributors, wholesalers, commission merchants and jobbers (middlemen), and retailers, clustered in downtown wholesale "produce districts" after 1850. In her Movable Markets: Food Wholesaling in the Twentieth-Century City (2019), Helen Tangiers chronicles a fascinating history of food processing and marketing centered around evolving regulatory structure and the 
physical space in which food was sold. Before 1850, food was regulated and sold exclusively through municipal-owned market halls later usurped by a free-market system of food provisioning more responsive to population concentrations and the introduction of modern transportation. ${ }^{7}$ Upon the loosening of municipal monopoly of the food trade to stimulate greater food supply, wholesale food economies aggregated large areas of downtowns in line with the rapid urbanization of the nineteenth-century city. Faneuil Hall Market in Boston, for instance, grew from 2.75 acres [1.11 ha] when it opened in 1826 to a 31 -acre [12.55 ha ] wholesale produce district by $1896 .{ }^{8}$ Produce districts were anchored by terminal markets, the retail endpoints for wholesale perishables, though certainly not the city's only retail venues given the abundance of market stalls, greengrocers, pushcart vendors, and hucksters distributed throughout the city. Large cities supported multiple terminal markets which became the economic and social centers of their respective downtown sectors (Fig. 1). Many will recognize the remnant urban fabrics of these produce districts, some with vestigial operations like the Eastern Market in Detroit, the Pike's Place Market in Seattle, the Chelsea Market and the South Street Seaport in New York City, the Strip District in Pittsburgh, and the River Market in Kansas City MO. Others, like the Faneuil Hall Marketplace in Boston, the Reading Terminal Market in Philadelphia, and the Grand Central Market in Los Angeles persist today as retail eateries and shops.

Like the nineteenth-century city, an even larger portion of the early twentieth-century city was occupied by perishable food processing and distribution when time-sensitive exchange among diversified actors drove a resilient market structure. Walter Page Hedden's 1929 classic How Great Cities are Fed is both a thick description of perishables' flow through the city (each food type followed different distribution channels before ending up in terminal markets) and a sumptuous photo/drawing essay chronicling New York City's now missing middle agricultural infrastructure. Hedden, an economist, discovered that the wholesale food market was "an aggregation of railroad yards, piers, sheds, streets, stores, sidewalks, wagons, and trucks. There is nothing static about this kind of market. In order to see all of it in operation, one must be continually on the move." ${ }^{9}$ The city was the market. Hedden's work is an unparalleled geographical description of the regional foodshed's role in shaping the city as well as its market structure governing food production, distribution, and consumption. ${ }^{10}$ Eventually, too many intermediaries became a problem. By 1910, Progressive Era reformers led by federal agencies, proposed to remedy food system inefficiencies and urban infrastructural inadequacies by consolidating food's complex web of social and economic relationships into gated suburban food terminals. ${ }^{11}$ Food was retreating from the city.

Capitalism metastasizes via enclosure processes and the privatization of assets once shared through the commons. We sometimes forget that enclosure is a strategy used as much by the public sector as by commercial 
interests (in the case of the former, the United States Department of Agriculture (USDA) and its promulgated rationalization of food marketing). ${ }^{12}$ Public-private initiatives hastened the capture of middle market structure by agrifood monopolies through the vertical integration of food logistics coupled with the institutionalization of contract growing..$^{13}$ Nonetheless, this is not a yearning for Hedden's food geography when cities governed the food trades and U.S. households (in 1919) spent an average of 36 percent of their annual income on food. ${ }^{14}$ Today the average is 9.7 percent. ${ }^{15}$ Rather, this is a reflection on the public goods (food sovereignty, security, and resilience) sacrificed with the disappearance of the middle market structure. Nor is this an uncritical locavorism to minimize food transport (food miles), recognizing that faraway places have a "comparative advantage" 16 in allocating resources to cultivate specialty crops like coffee beans, tea, grains, indigenous fruit, oils, etc. Structure is information; and reclamation of the intelligence, appropriate technologies, and resiliency lost to monopoly market structure is urgent since serious fault lines are appearing in the industrialized food complex, explored below.

\section{The Withdrawal of Food from the City}

Regional foodsheds distinguished by a self-organizing middle market structure worked interdependently with continental-scaled food supply chains until their eclipse by the latter during post-WWII prosperity. By the 1920s, costly inefficiencies in food handling among layers of market middlemen prompted North America's largest cities to build wholesale food terminals, ${ }^{17}$ mostly in suburban areas extending what the railroads started

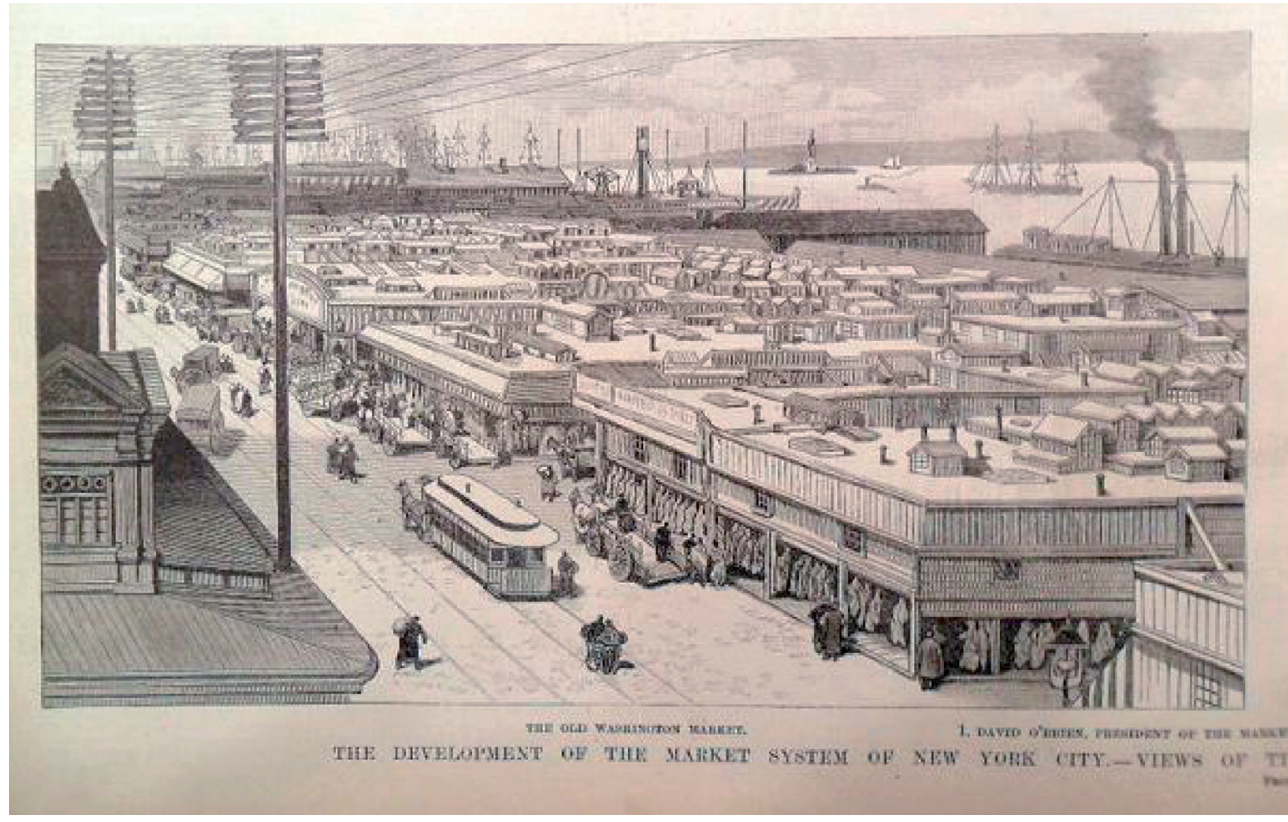

Figure 1. Historic Washington Terminal Market in New York City with over 500 food vendors at its peak, demolished in the 1960s. 
with their decentralization of slaughterhouses and food processing. These large wholesale distribution complexes for fresh food maintained logistical support for independent farmers and downstream local food businesses, while providing diversified products unavailable in chain supermarkets. Successors to the city center produce district, food terminals rationalized distribution, centralized quality control, and reclaimed wholesale functions being lost to monopoly grocers' own private distribution centers. New York City's Hunts Point Terminal Produce Market, for instance, the largest in the U.S., handles 65 percent of the city's wholesale produce sales. ${ }^{18}$ Landscape urbanist Pierre Bélanger notes the market pluralism fostered by another large North American food terminal, the 40-acre [16-ha] Ontario Food Terminal (OFT), writing:

The terminal works as a leveler. An arm's-length governmental organization operating on the principle of just-in-time delivery, it ensures fair market competition. The terminal especially benefits small and medium-sized businesses that have strong demand for produce but limited storage and handling capacity. They need fast turnaround times and fresh goods daily. The terminal aggregates 3,100 independent grocery stores, 1,172 franchise stores, and over 600 growers and farmers in Southwestern Ontario. The site houses a farmers' market with 550 stalls and a warehouse market with $7,500 \mathrm{~m}^{2}$ [80,729 sq. ft.] of cold storage and 1,400 $\mathrm{m}^{2}$ [15,069 sq. ft.] of dry storage. It is equipped with a 575-car parking deck, two cafes, and a restaurant. Like a miniature city, it even has its own centralized garbage collection and police force. ${ }^{19}$

The continent's largest twenty-five cities that built public food terminals, ${ }^{20}$ parallel to those of monopoly grocers, maintain supply chain redundancy (a primary feature of resilient systems). Remnant middle food economies deliver outsized multiplier benefits to metropolitan areas that invest in food commons infrastructure. Again, Bélanger on the OFT's stimulative effect on local business incubation:

The OFT has indirectly contributed to the growth of greenhouse operations throughout Ontario, which has the fastest growing concentration of greenhouses in North America. Greenhouse operations in Leamington, Ontario are doubling their operations every five years. The terminal also functions as a generator. Spin-off effects include more than 600 companies, ranging from food processors and packagers to customs brokers and freight forwarders that employ over 40,000 people. Fueled by diverse demand from Toronto's 347 documented ethnicities, the OFT serves the largest, most important manufacturing sector in the city and has established a unique and irreversible connection with all levels of the food system: metropolitan, continental, and global. ${ }^{21}$ 
Those cities without food terminals and similar middle market institutions leave more than two-thirds of the U.S. population reliant on opaque monopoly supply chains where, except for the grocery store, food has essentially disappeared from the city. Monopoly supply chains performed well throughout the pandemic, but consumers will be susceptible to collapses forming within monopoly market structure.

\section{PERILS IN MONOPOLY MARKET STRUCTURE}

While the plight of independent farmers during the COVID-19 pandemic has been quite visible, large contract growers are entangled in their own slowboiling but less visible crisis. Crop concentration (horizontal integration) and monocropping production are quickly depleting the very ecosystems upon which monopoly structure relies. Amidst the abundant literature on the unsustainability of industrial agriculture as a production logic, energy tells the story best. Whereas just a hundred years ago agriculture spent one calorie to yield ten calories in food, the U.S. fossil-fuel based agricultural system today spends up to ten calories to gain one calorie of food, ${ }^{22}$ the very definition of unsustainability. Food economics author Tom Philpot in Perilous Bounty: The Looming Collapse of American Farming and How We Can Prevent It (2020) chronicles the alarming productivity declines in the nations' two largest farming clusters: California's Central Valley, and the Upper Midwest Corn Belt with lowa at its center. ${ }^{23}$ Both reflect general trends and probable endgames in U.S. agriculture based on cascading ecological failures that accompany the drive to maximize yield.

Astonishingly, the Central Valley occupies less than 1 percent of the nation's farmland yet it produces one-quarter of America's food (90 percent of broccoli, carrots, garlic, celery, grapes, plums, artichokes, etc.). ${ }^{24}$ Paralleling the Central Valley's intensive agricultural production, the Corn Belt's corn-soybean-meat complex grows 35 percent of the world's corn (90 percent of U.S. production, the nation's largest crop), and 80 percent of the nation's soybeans. ${ }^{25}$ Overproduction in both regions is consuming the natural resource base on which monopoly agrifood depends: water in the Central Valley, and arable soil in the Corn Belt. Their ecosystems appear to be slipping past the point of no return.

Water shortages are conspiring to end California's supremacy in vegetable and fruit production, particularly in the semi-arid Central Valley, home of the largest concentration of irrigated vegetable production in the country. Shifting weather patterns attributed to climate change are hindering water supply sourced from once dependable Sierra Nevada snowmelts, exacerbated by local aquifer drawdowns and the salinization of farmlands using aquifer-based irrigation. Vanishing groundwater has already ended California's production of rice and cotton, as "California's farms are essentially mining nonrenewable water." ${ }^{26}$ Resolution of disputes between cities and farmers over allocation of the state's fixed water budget will not 
favor farming, particularly since agricultural water use in this water-stressed state has been heavily subsidized. Farming represents just 2 percent of California's economy yet "consumes three times as much water as all other human activities" ${ }^{27}$ guaranteeing further decommissioning of farmland.

Likewise, the Corn Belt's industrialization of corn and soybean production over the last fifteen years incented the race to densely plant every available parcel of open land, now equal in size to one and half times the land area of California. Philpot argues that corn essentially became an "industrial input" to a massive processed-food industry in the U.S., and livestock feed for an exploding global meat industry particularly in China, where arable land, water, and cheap grain are not as abundant as they are in the U.S. ${ }^{28}$ Agrichemical (food) companies provide proprietary turnkey crop production solutions combining seed-fertilizer-pesticide inputs for application by growers. Not surprisingly, their outputs overshoot the carrying capacity of Corn Belt landscapes to metabolize these waste streams. Crop overproduction combined with hotter temperatures and more frequent epoch storm events have led to widespread soil erosion and severe watershed degradation. Citing lowa State University researchers, Philpot reports the soil erosion rate in lowa to be sixteen times the natural soil-replacement rate,${ }^{29}$ compromising ongoing farming productivity and solvency.

Unfortunately, the hyper-efficiency organizing monopoly market structure shoves aside regenerative farming approaches designed to avoid the ecological downsides of industrial farming. Regenerative growing techniques include the use of cover crops, crop rotation, crop socialization employing symbiotic planting strategies, organic farming, and integration of animal husbandry with crop production, all delivering "ecological services" 30 including erosion control, soil health, and carbon sequestration. The diminishing capacity of monopoly structure to socialize the outsized costs of its negative externalities, coupled with independent farmers' growing abilities to monetize public goods in more holistic business models (e.g., organic certification, organic fertilizer production, value-added products, carbon sequestration and other conservation services, ecotourism/ education, and fair trade), will accelerate further splintering of the food market. As monopoly food's geography of concentration and specialization grows more unmanageable, middle market supply chains are better positioned to answer food's intrinsic complexity, ignored for decades.

However, direct sales will not feed the country and, as we saw during the pandemic, it was a fragile exchange, lacking the structure of resilient food supply and distribution. While farmers' markets are important purveyors of consumer education and food literacy, most farmers do not enjoy retail duty and their net gains (factoring time and costs), averaged across much anecdotal literature on the subject, appear to equal minimum wage. Farmers' markets account for less than 1 percent of domestic farm cash 
receipts ${ }^{31}$ and thus are not a market force in the U.S. for many unfortunate reasons. Food cooperatives, arguably, have a more promising future since they offer food hub-like services to local farmers through stable retail venues. The good news is the pre-pandemic boom in direct sales reflected enlightened procurement approaches among local institutions seeking healthy and nutritious food sourced from socially responsible product chains, the semblance of a food commons. We are seeing the reemergence of short food supply chains for several reasons: consumer demand for diversified and healthy food; response to climate change rendering some growing regions non arable; local economic development based on cooperative structure; food security; and ecosystem stewardship; among others. Middle-sector agriculture needs a different kind of infrastructure. Like other knowledge-based industries, food is recognizing once again the city as an important human resource for innovation, information exchange, and cooperation in the creation of markets.

\section{FOOD HUBS: THE REEMERGENCE OF MIDDLE MARKET STRUCTURE}

More than 90 percent of Hawaii's food is imported from U.S. monopoly supply chains despite being the most remote population center in the world (this is ironic, given the state's recognized commitment to local food). ${ }^{32}$ Once a food-exporting nation before its annexation by the U.S. in 1898, Hawaii shifted to a dual-crop plantation economy dominated by sugar and pineapples in the twentieth century. Since the departure of agrifood's plantation economy to lower-wage countries, the state is moving toward diversification and expansion in its local food production as part of its "Hawaii 2050 Sustainability Plan." Hawaii's comparative disadvantage due to its remoteness highlights the essentiality of middle market structure in mitigating risks and community resiliency deficits like food insecurity. High input costs for capital, land, labor, and regulatory compliance, coupled with limited access to abundant water, are barriers preventing the next generation's entry into farming. Incongruously, it is now more cost effective for cattle raised in Hawaii to be flown on Boeing 747s to the U.S. mainland for finishing due to limited availability of local feed and inadequate slaughtering facilities, despite the islands' year-round grazing season. ${ }^{33}$

Food system planning to develop a portfolio of food production facilities for serving Oahu was led by the University of Arkansas Community Design Center and the UA Resiliency Center with a team of ecological engineers, landscape architects, urban designers, architects, farmers, and food scientists, in partnership with Hawaii's Department of Agriculture, Agribusiness Development Corporation, and State Senate leadership during 2016-2019. Oahu is the state's most populated island of eight, with 980,000 residents encompassing 69 percent of the state's population including Honolulu. Proposed infrastructure components included the "Whitmore Food Hub Complex" for processing of fruits and vegetables, the University of Hawaii-based "Wahiawa Value-Added Product Center" (a food 
product innovation center) for incubating value-added food and cosmetic products, and post-harvest "Farm Base Yard Processing Prototypes" for food and value-added processing on remote farms (Fig. 2).

Island grocers stock only five days of food, so Oahu is fifteen meals away from anarchy upon any major disruption to its just-in-time supply. The state's goals in localizing food production are to increase food security and resiliency in its food provisioning network. A cooperative food hub complex serving a short food supply chain will be tailored to small farmers and independent food businesses. Hawaii is a state of small farmers: 93 percent of Hawaii farms are family farms and 93 percent of farms reported less than $\$ 100,000$ in annual sales, qualifying as "small farms." ${ }^{34}$ Two-thirds of the state's farms are smaller than nine acres [3.64 ha]. The state will provide upstream assistance to farmers through low-cost-lease land for growing while enabling access to repurposed irrigation infrastructure abandoned by corporate plantations. This should incentivize new farm start-ups in building the next generation of farmers (the average age of a Hawaiian farmer is sixty years). ${ }^{35}$ Downstream economic development objectives include business incubation centered around substitution of local food products for imports, and increased development of a skilled agricultural and food science workforce.

Food hubs are a reemerging middle market infrastructure to support the aggregation, processing, and distribution of food grown by independent farmers. ${ }^{36}$ The shift from a pluralistic food system of intense connectivity to an oligopolistic structure relegated independent farming to alternative forms of growing and direct-to-consumer sales lacking middle market support.

Besides the costs associated with processing and distribution, independent farmers are challenged by new food safety regulations stipulated by the national Food Safety Modernization Act (FSMA), passed in 2011 and enacted through a phased rollout over the past decade. For small farms, already low-margin enterprises, the compliance costs are estimated to be as high as 7 percent of annual sales, while the USDA estimates costs of just 0.33 percent of annual sales for the largest farms. ${ }^{37}$ Not only will the food hub socialize the high costs of post-harvest food production among independent farmers, but its collective brain will empower small-farm enterprise through information exchange and skills/trade development akin to guilds. The challenge in developing non-corporate food hubs, then, entails the formulation of fitting business models ${ }^{38}$ and appropriate facility designs, despite scant case studies and comparable data to guide planning.

Though food hubs may sponsor retail functions, by definition they are not retail or farmers' markets since direct sales is not their objective, according to the USDA. ${ }^{39}$ Rather, food hubs are supply chain channels for building sustained wholesale relationships among diversified producers and bulk-oriented customers like grocers, schools, universities, hospitals, and 
restaurants, reducing transaction costs for both. ${ }^{40}$ They are "market makers" for locally produced food, providing for-profit services as well as public goods in catalyzing a food commons. Food hubs centralize post-harvest services that lower input costs related to safety compliance, processing, storing (especially expensive cold chain storage), marketing, packaging, and distributing locally produced food. Cooperative arrangements governed by transparency and information flow raise the plausibility for implementing market-enhancing sustainability programs. Food hubs can readily leverage middle market structure to build new "value chains" ${ }^{41}$ when overlapped with other community systems like rural workforce development, agriculture workforce housing, food business incubation, food banking, cultural tourism, waste upcycling, and urban design. Food hubs are well positioned to rethink waste management where agricultural waste streams become feedstocks to other food operations, the kind of material upcycling seen in industrial zero energy districts. Food hubs' spillover effects often deliver invaluable nonmarket benefits as "hub operators represent a new kind of food entrepreneur, one that is demonstrating a financially sound business model that can be both market and mission driven." ${ }^{42}$ Connectivity and pluralism build resilience.

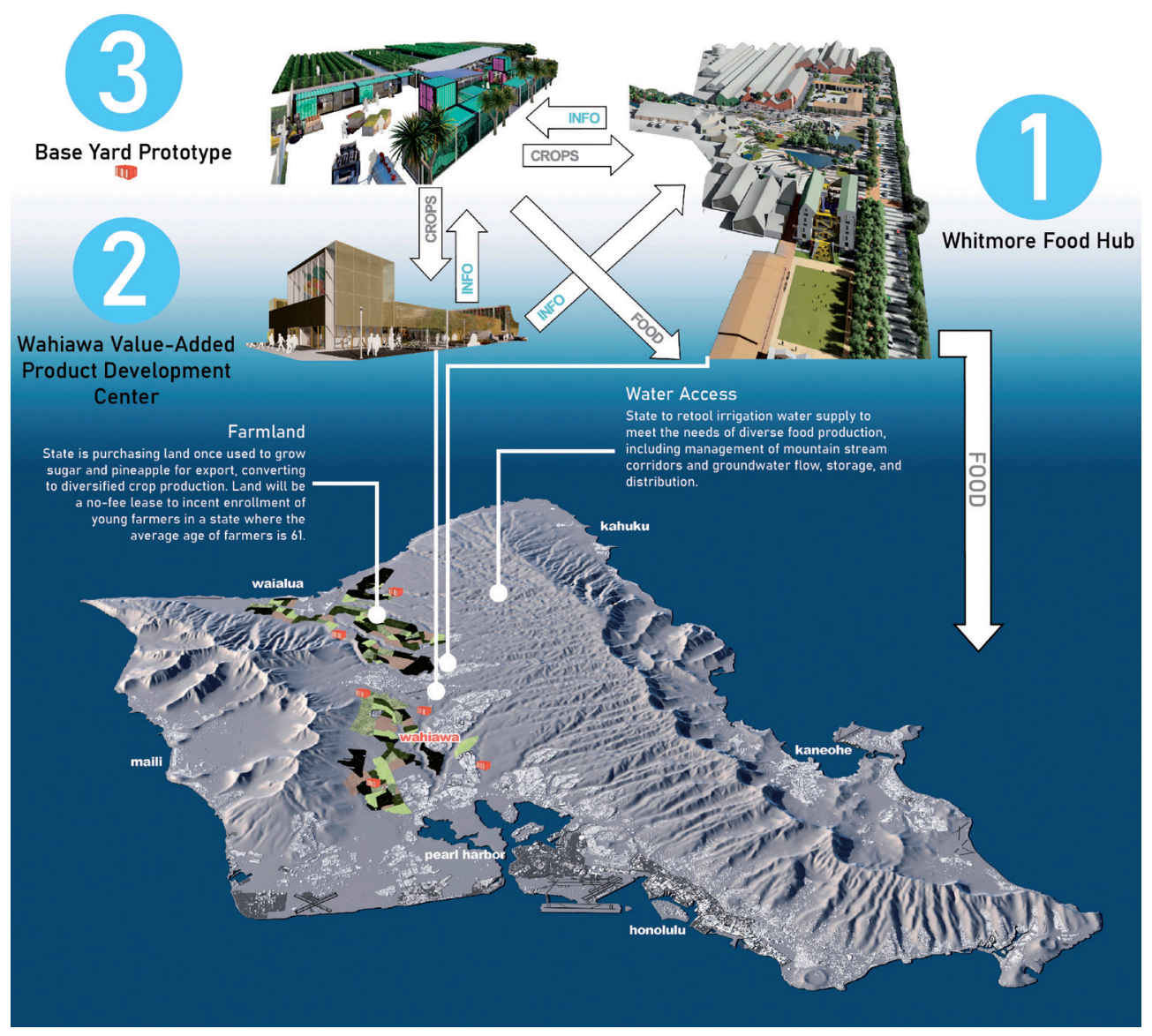

Figure 2. Development of middle market agriculture infrastructure for Oahu Island. 


\section{HAWAII'S WHITMORE FOOD HUB COMPLEX}

Located in Oahu's central agricultural plains between the island's two coastal mountain ranges, the proposed Whitmore Community Food Hub Complex is a post-harvesting facility for the wholesale processing and distribution of fruits and vegetables. The complex supports incubation of a place-based artisanal food ecosystem, including coffee roasters, distilleries, tropical juicing plants, producers of kimchee, pickled product, taro (poi) and breadfruit (ulu), and food-grade cosmetics. The 34 acre [13.76 ha] complex repurposes an abandoned Dole maintenance facility across the canyon from downtown Wahiawa (population: 17,400), the island's traditional agricultural service center twenty miles north of Honolulu.

\section{Community Participation}

Using design thinking, the Department of Agriculture and State Senate leadership collaboratively led development of food policy and planning of an island-wide food supply chain aligning small growers with wholesale consumers. In partnership with Wahiawa civic organizations, state leadership co-created the food hub complex program with other state agencies in housing, technology, finance, and transportation to address cross-sectional complexities in food systems. Official hearings and open workshops were conducted at the State Capitol in Honolulu, while community design workshops were conducted in Wahiawa. Agricultural officials primarily wanted a high-performance food hub facility operating over three daily shifts to serve logistical needs without the complexities of nonagricultural functions. Conversely, Wahiawa residents and State Senate leadership held equally important interests in greater job creation, sustained economic development including tourism, allied business incubation, provision of affordable housing for the agricultural workforce, and retail facilities including a farmer's market (Fig. 3). Neighbors surrounding the site in Wahiawa viewed the food hub complex as a neighborhood center. The urban design challenge, then, was to provide a neighborhood anchor for the surrounding Whitmore Village as well as cultural attractions appealing to the larger North Shore visitor community despite that 80 percent of the complex is devoted to logistical functions (Fig. 4).

\section{Logistics}

Food safety is an important public health issue backed by a new regulatory regime. The food hub is designed to meet the science-based protocols in the FSMA safety regulations mandating preemptive security management throughout all food system facilities. The goal is to prevent food contamination, mostly from human error, rather than simply respond to foodborne illness outbreaks. The FSMA requires comprehensive hazard analysis, preventive control throughout all growing and production processes, and health and safety controls in facility design and operations. 


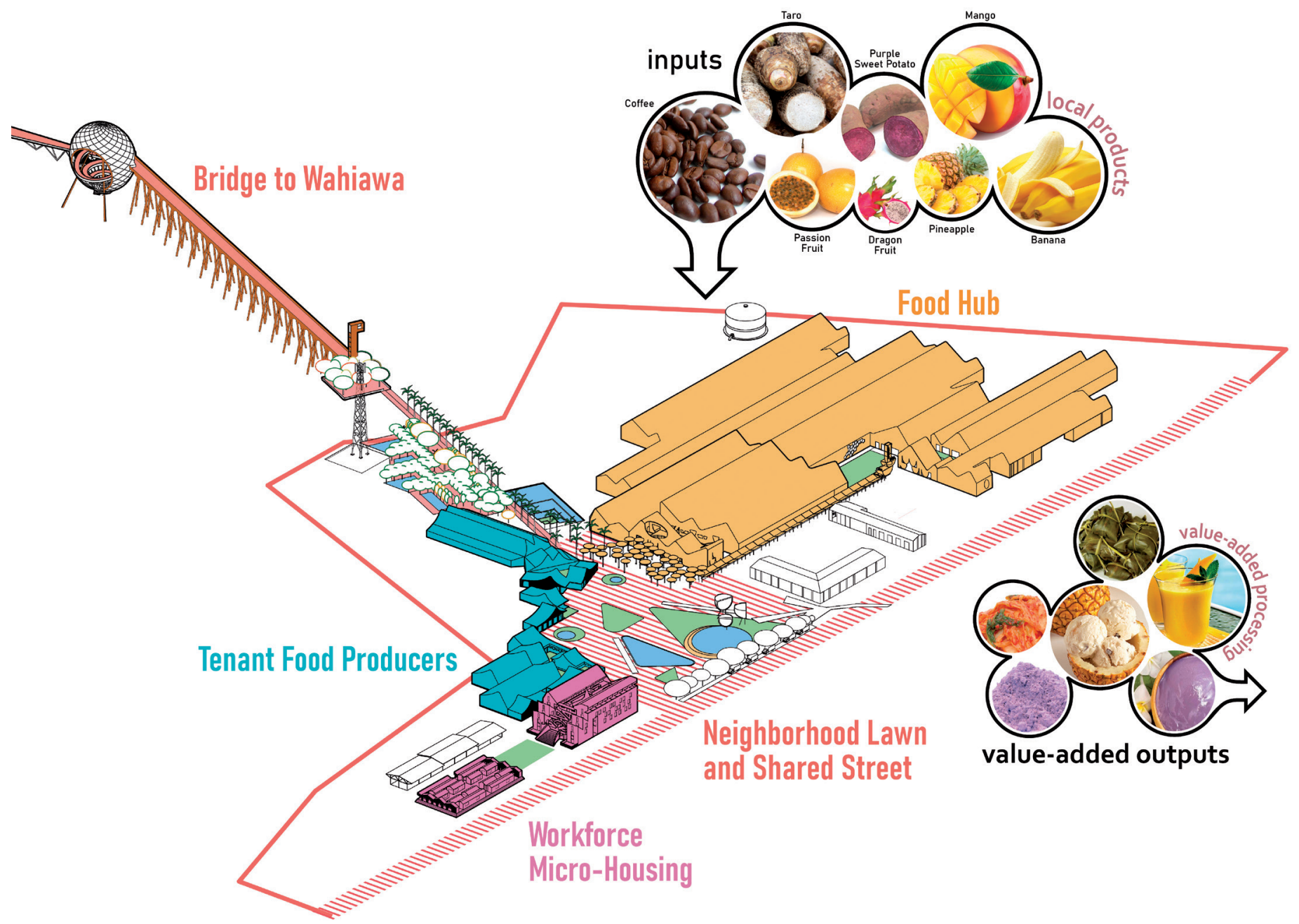

Figure 3. Components in the Whitmore Food Hub Complex.

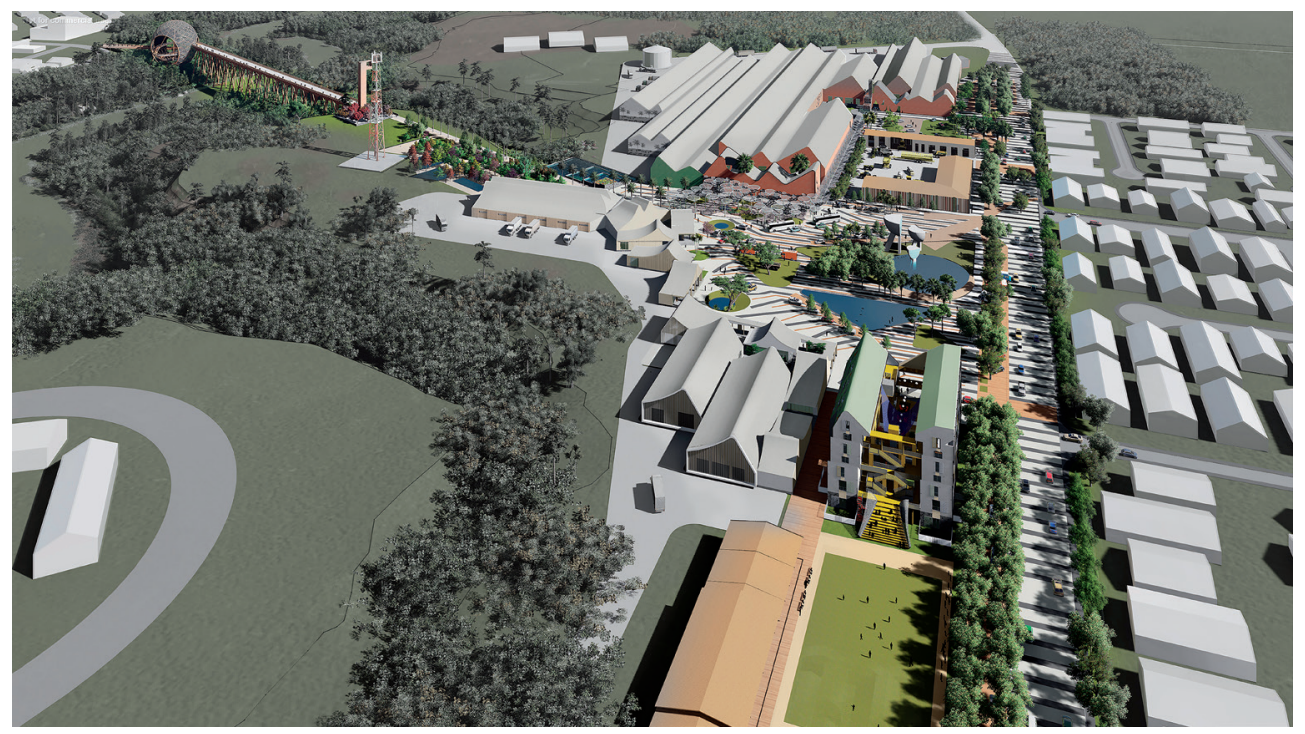

Figure 4. Whitmore Food Hub Complex and retrofit of Whitmore Avenue on north side. 
Facility construction should minimize articulation and joinery to prevent water and pest intrusions, while resisting mold, mildew, and bacterial growth. Exterior cladding should be resistant to weathering including corrosive effects from salt, and interior surfaces must be durable and easy to clean through regular power washing. Accordingly, the food hub facility employs tilt-wall concrete construction, an in situ construction system common among investment-grade logistics facilities. Tilt-wall concrete systems optimize food safety in the context of local environmental stresses, including severe weather, earthquakes, high humidity, and corrosive climate conditions. The design challenge involves deriving a civic architectural expression from a building construction system lacking architectural and place-making pedigrees (Figs. 5-7).

A centralized food hub facility with a visitor center at 75,000 sq. $\mathrm{ft}\left[6,968 \mathrm{~m}^{2}\right]$ is the minimum operating segment for a Phase I facility, managed as a producer cooperative. Its eventual build-out will be 375,000 sq. $\mathrm{ft}$ $\left[34,839 \mathrm{~m}^{2}\right]$. The FSMA regulations necessitate the sorting of food products between incoming and outgoing streams with protected areas among them

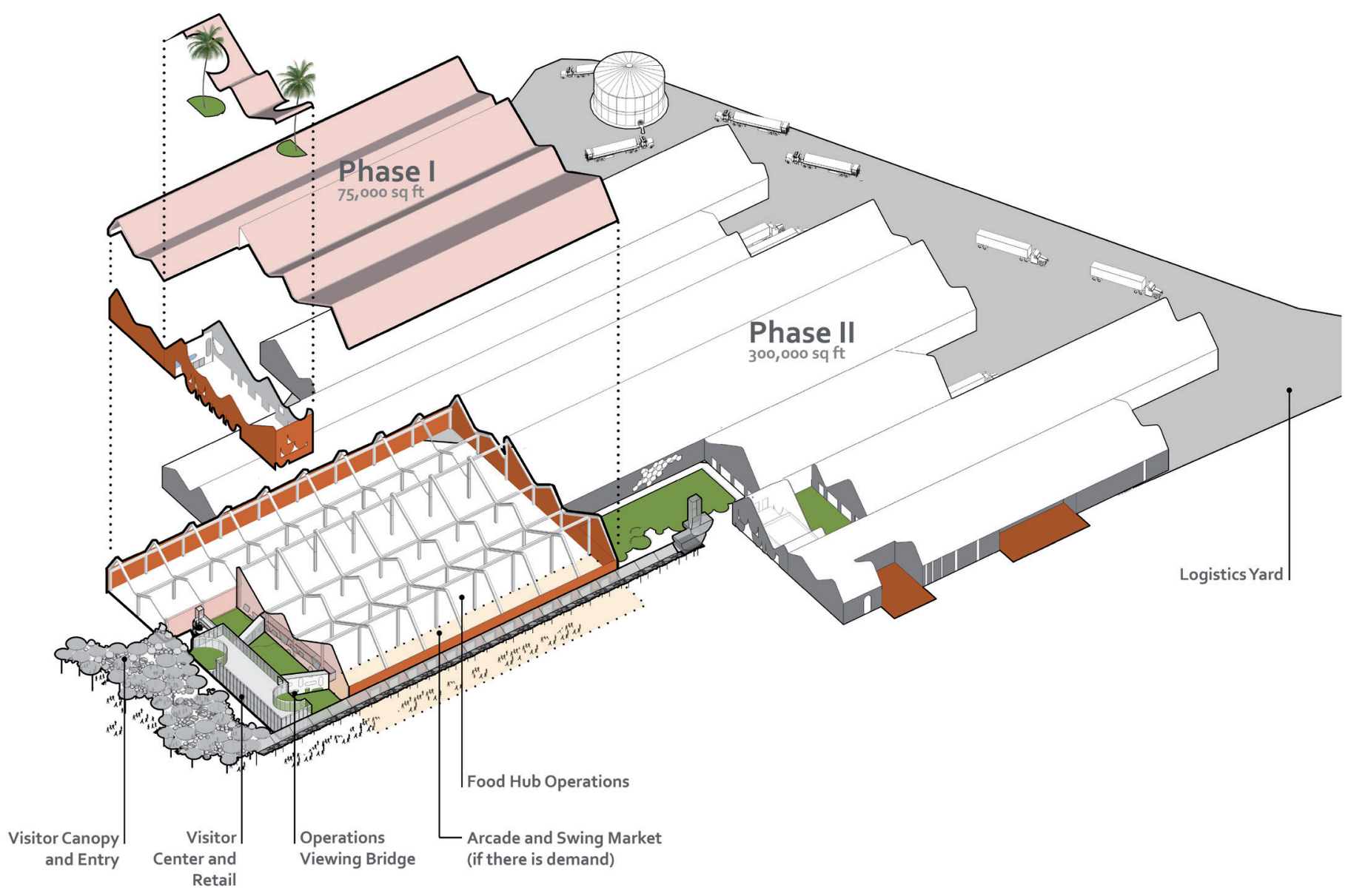

Figure 5. Axonometric of food hub facility phasing: visitor side vs. logistics side. 


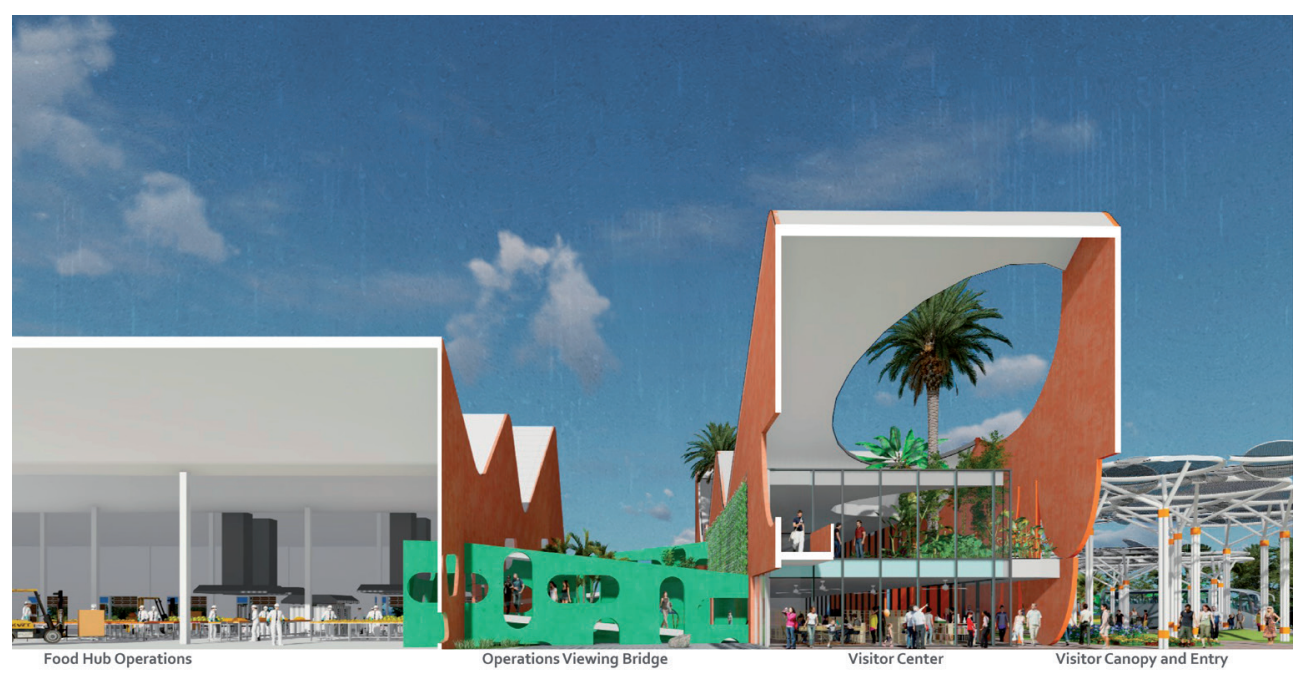

Figure 6. Socializing the big box: visitor center and viewing bridge to food hub operations.
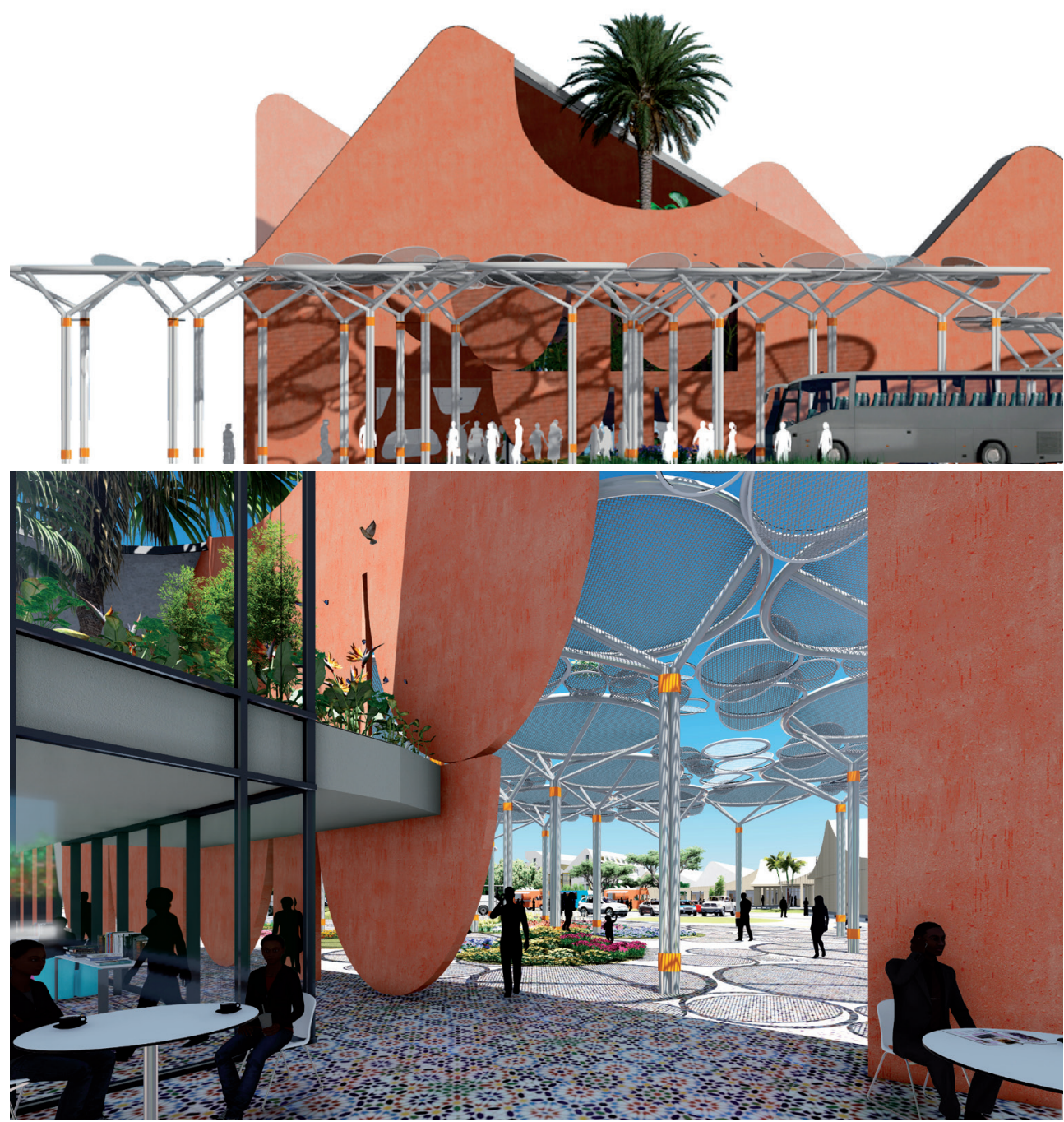

Figure 7. Tilt concrete wall system shaped for public entry and facilities. 
for washing/sorting, and processing/packaging. Unlike pre-FSMA food facility operations, visitor tours of operations will be highly circumscribed, creating opportunities for the development of novel building frontages that maintain visitor engagement with contaminant-free production environments. Opposite this, continuous outdoor logistics yards for product aggregation and distribution, water treatment/storage, and waste management border the site's eastern and western edges away from public view.

The Hawaiian Islands enjoy rich subaltern traditions of food innovation, but entrepreneurs lack the venture capital and market structure required to scale up product distribution beyond informal farmers and roadside venues. State officials authorized an additional $60,000 \mathrm{sq}$. $\mathrm{ft}$. [5,574 $\left.\mathrm{m}^{2}\right]$ for satellite tenant facilities open to established food businesses, alongside incubator space for new businesses. Officials recruited established food businesses to be anchor tenants at the food hub complex, especially those which offer facility tours. Prospective tenants include coffee roasters, breweries/ distilleries, juicing plants, taro producers, and other heritage food producers who desire their own freestanding structures and identities to support proprietary operations and secured customer bases.

\section{Place-Making}

The complex serves allied community needs in agricultural workforce housing, business and technology incubation, and cultural tourism requiring an island-wide destination. More a campus than an industrial park, the public space network modulates the complex's growth and fit within its surrounding context. Contrary to a fine-grained urban fabric, the food hub's warehouse economy requires large-scale horizontal processing and storage environments to support wholesale exchanges. Public space is both a means and end to coherently negotiate uneven differences: between big scale and small scale, residential function and industrial function, and civic space and logistical space.

The master plan stratifies circulation systems between public and logistical functions. Public areas of food hub buildings front a signature neighborhood lawn much like a village green serving all of Whitmore Village. The lawn provides neighborhood identity within the vagueness of Whitmore Village's auto-oriented suburban layout. The neighborhood lawn connects Whitmore Avenue to the north with the food forest and a pedestrian/bicycle bridgecum-botanical-garden linking downtown Wahiawa to the south (Fig. 8). Agnostic of use, form-based design guidelines require industrial buildings to qualitatively define public space. Shared civic expression in sun canopies, porches, loggias, arcades, and gardens and courts draws on the lessons of architectural shade economies developed in tropical public realms (Fig. 9). This includes spaces planned for workforce micro-housing. 


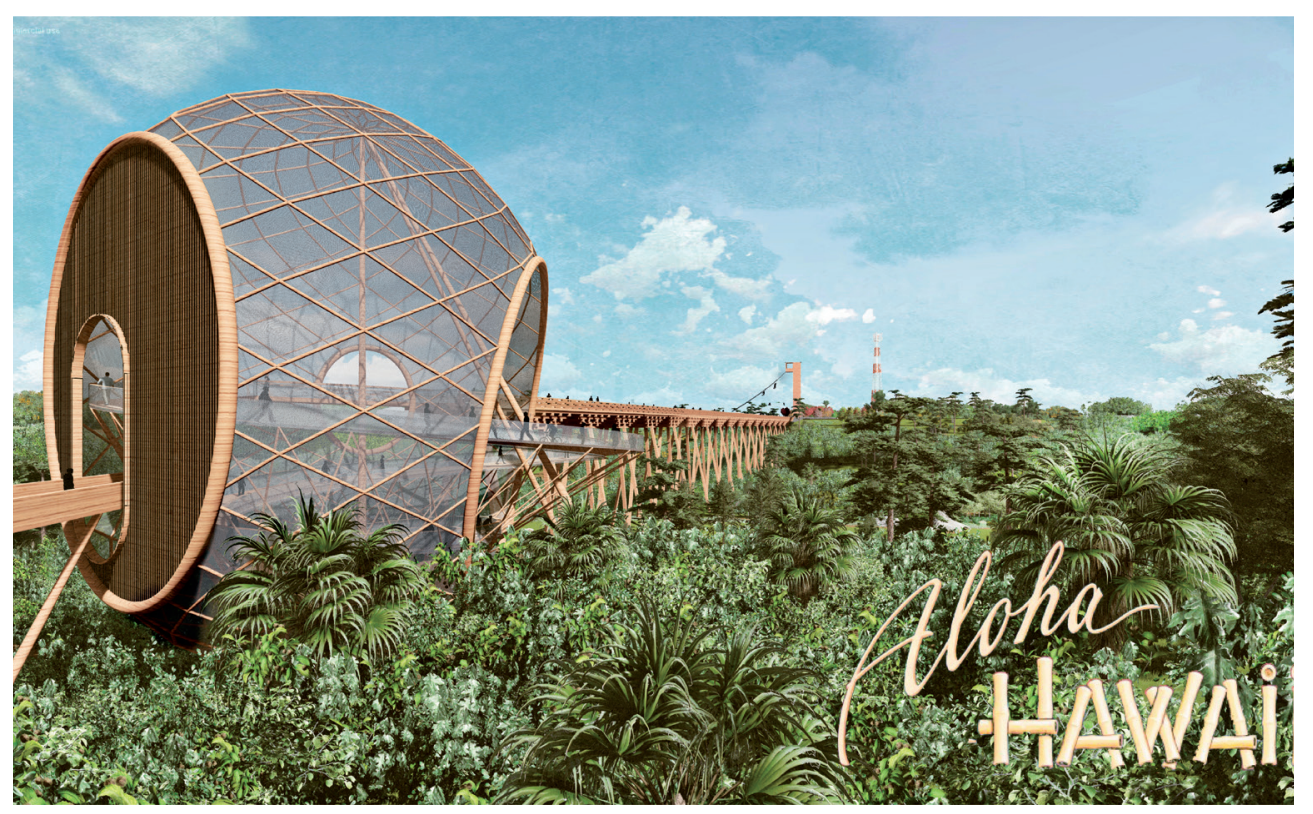

Figure 8. A new Oahu icon? The NEST, a botanical pavilion with hanging gardens terminating new bridge and zip line over the Kaukonahua Stream.

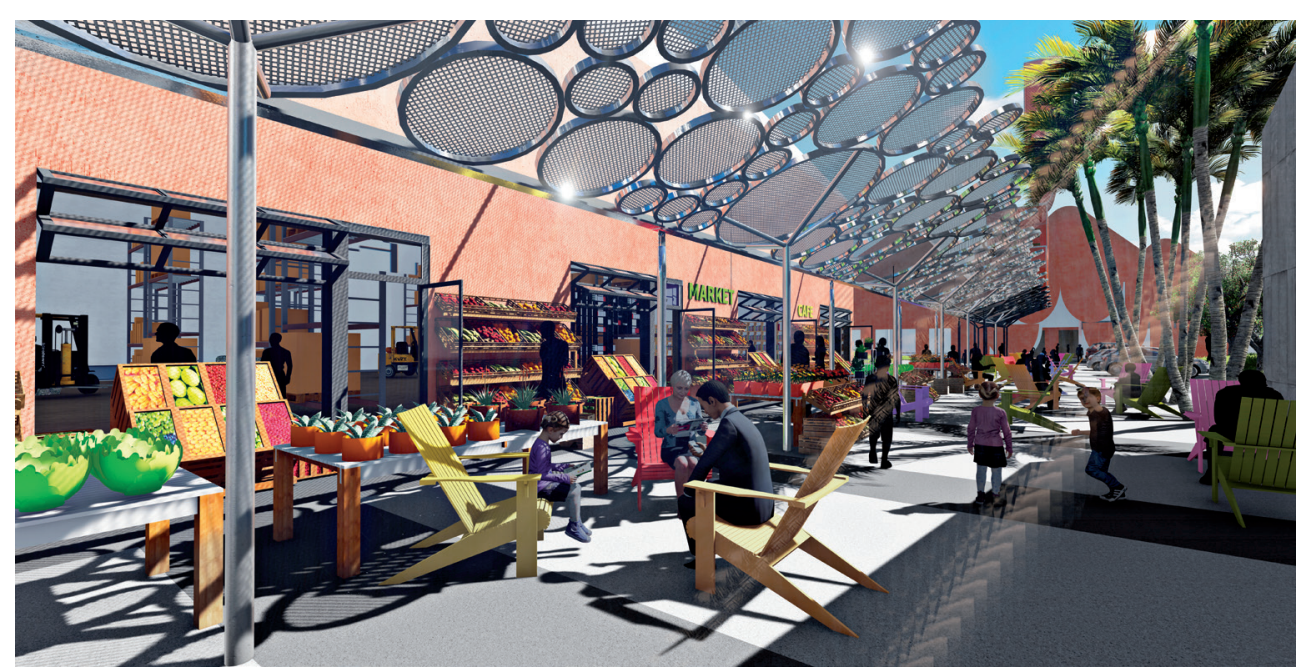

Figure 9. Farmers market along the edge of the food hub.

What is good for Hawaii's agricultural workforce is good for agriculture. Whereas the production chokepoint for meat statewide is the cost of feed, for fruits and vegetables it is the cost and availability of labor. ${ }^{43}$ Hawaii is the nation's most expensive housing market and suffers the highest rate of homelessness, particularly among its low-income agricultural workforce. In 2015, Governor David Ige declared a state of emergency around homelessness in Hawaii. According to the USDA, in 2013, farm operators in Hawaii paid their workers equal to an annualized rate just under $\$ 24,00044$ in a state where the average household income was over $\$ 69,000 .{ }^{45}$ Many Hawaiian farm workers live in unconditioned informal shelters on farms, 
including barns and food processing facilities (sometimes the same thing) all clear violations of FSMA regulations. Foresightful state leadership mandated incorporation of a transitional housing solution at the food hub complex. Thus, the plan incorporates workforce micro-housing with wraparound social services and job skills training to improve the quality of life for essential workers who often lack homes and cars.

The housing complex fronts the eastern edge of the neighborhood lawn and sits atop the research and innovation hub on the ground floor. A five-story loft structure of one hundred single-occupancy dwelling units between 250-300 sq. ft. [23-28 $\mathrm{m}^{2}$ ] surround an exterior elevated courtyard within the housing block. Courts, patios, screened porches, arcades, and recreation fields offer public places that channel time socially outside of work. Bordering the south edge of the recreation fields, a refurbished exterior industrial shed (now a community super roof) houses a basketball court, social services offices, and indoor gathering space completing a shared landscape that extends the modest interior spaces of the dwelling units (Figs. 10-12).

Water is used to curate key public spaces, especially in the food forest and the taro wetland garden showcasing permaculture growing techniques using legacy plant communities. The complex at build-out requires approximately two million gallons of potable water daily. Since local water supply is unpredictable in meeting peak demand, site design incorporates a supplemental water harvesting and storage landscape, including water towers to ensure pressurization and adequate fire suppression capacity. Storage towers standing in the lawn's pond double as landmarks celebrating Hawaii's agricultural heritage. Water towers project archival images of plantation-era life interchangeable with representations from the pre-colonial ahupuaa (wetland-based food production system), providing historic context for visitors. Here, water systems are used to construct the physical site while memorializing agricultural heritage in the shaping of culture (Fig. 13).

\section{WAHIAWA VALUE-ADDED AGRICULTURAL PRODUCT DEVELOPMENT CENTER (VAC)}

The proposed VAC repurposes a 33,000 sq. $\mathrm{ft}$. [3,066 $\left.\mathrm{m}^{2}\right]$ metal warehouse in downtown Wahiawa as a food innovation makerspace for the University of Hawaii Community College System in collaboration with the Department of Agriculture. The VAC supports a new food science design curriculum focused on incubation and commercialization of value-added food products made from nearby agricultural waste streams, one of a few such programs nationwide. Hawaii is an established leader in culinary studies and the schooling of chefs and food workers to serve the tourist industry, but industry profits are captured by global hospitality chains which leave the state. Conversely, local product development exemplifies Jane Jacobs' 


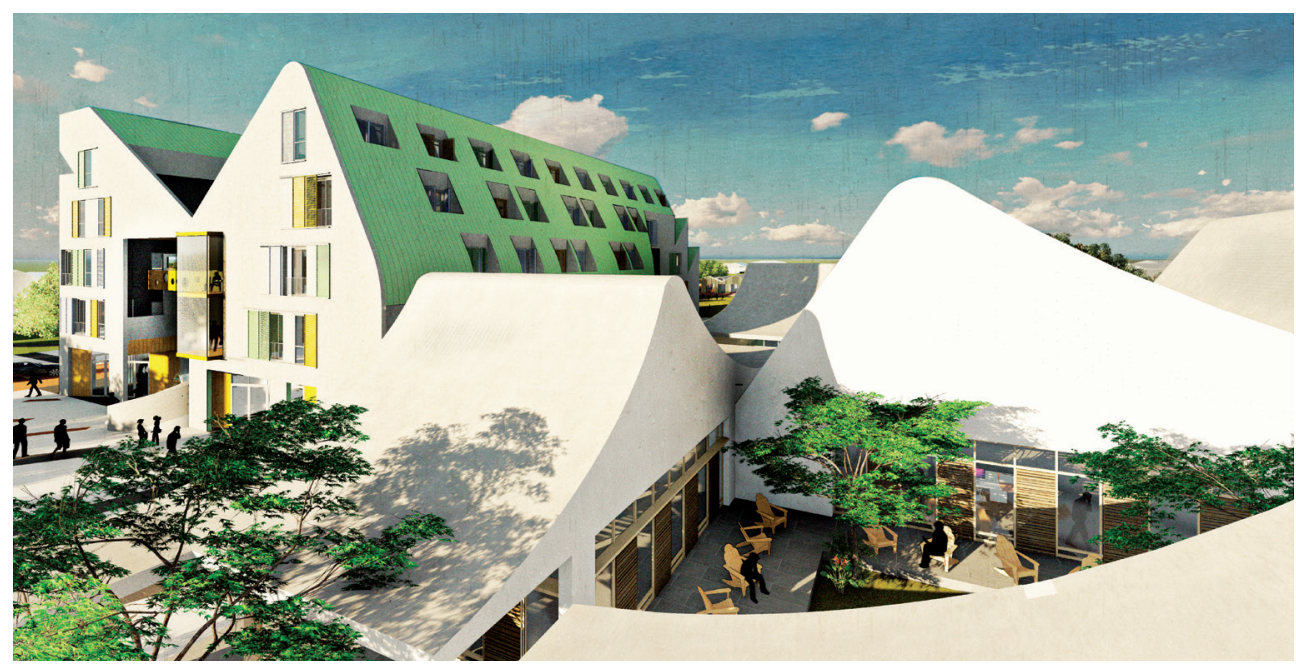

Figure 10. Loft micro-housing for agricultural workers on lawn with tenant food businesses in foreground.

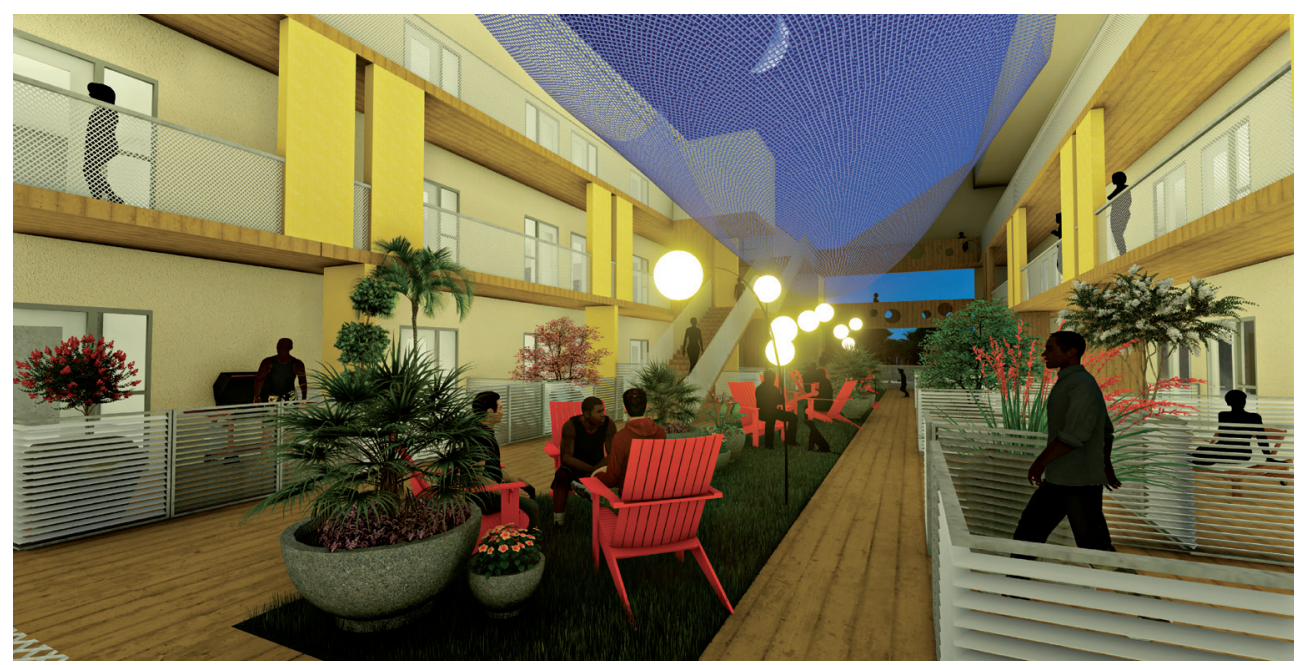

Figure 11. Elevated courtyard in housing complex with a hundred dwelling units.

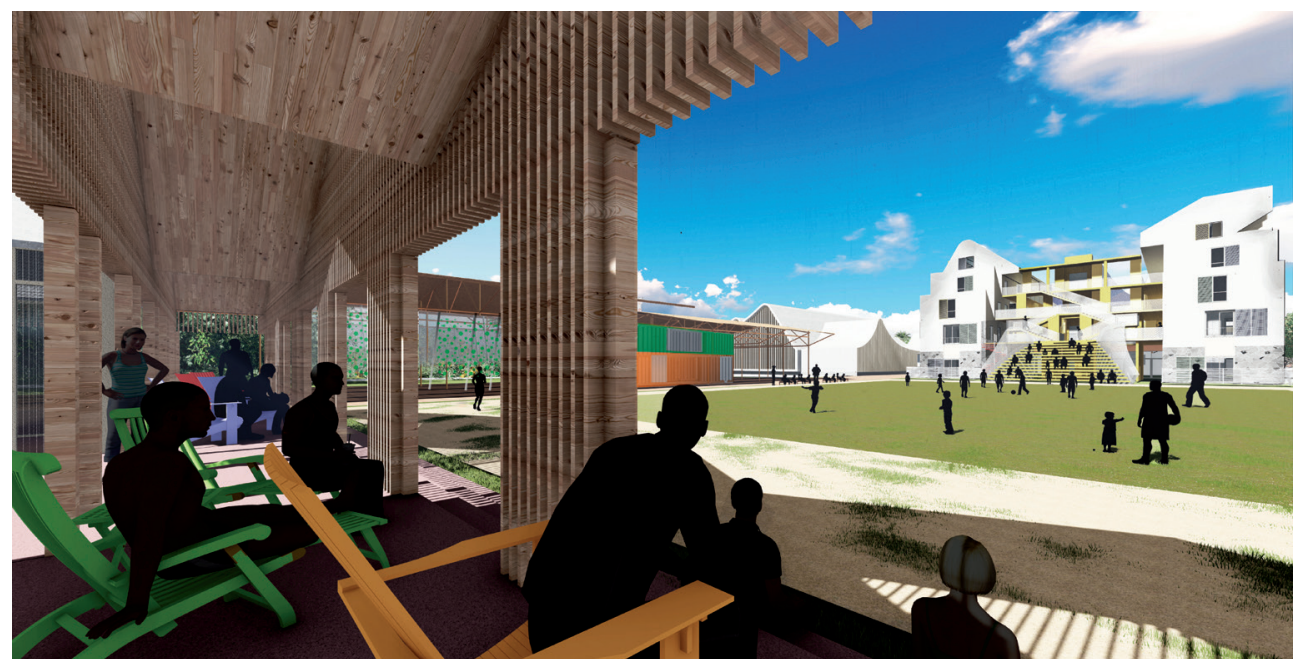

Figure 12. View from patio housing for agricultural workers overlooking playfields. 


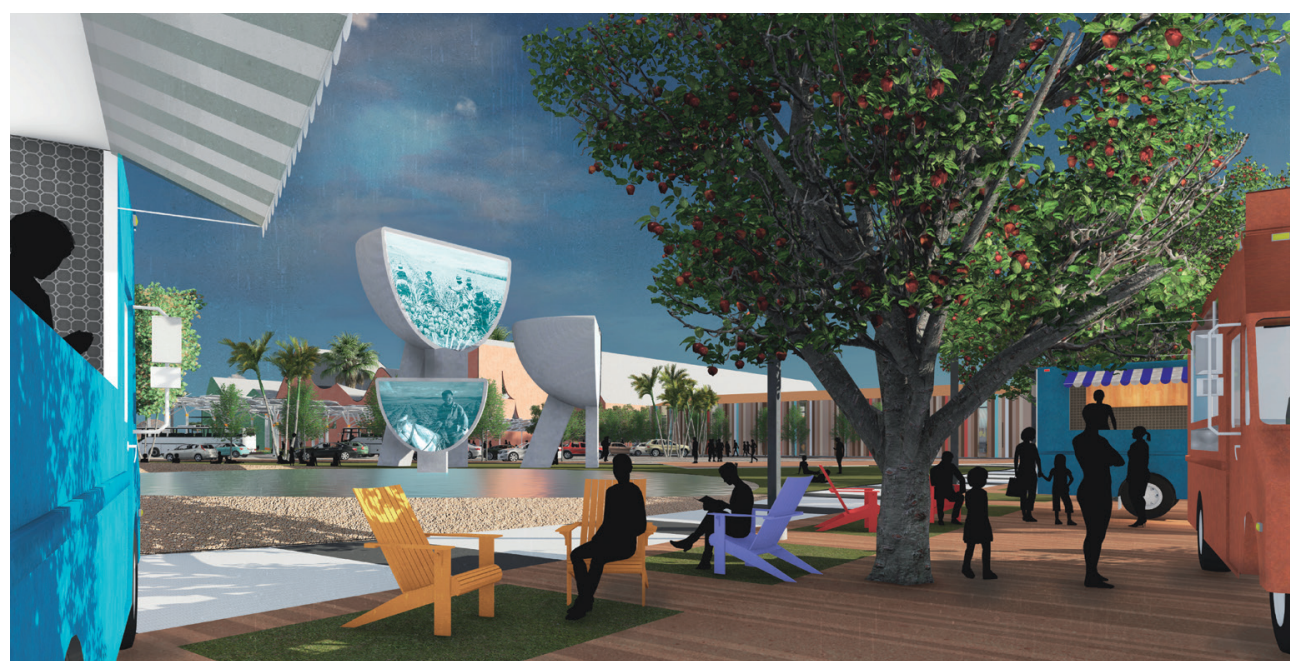

Figure 13. Water storage towers on neighborhood lawn double as imaging system showing regional agriculture heritage.

notion of "import replacement." "Economic life 'develops' by grace of innovating: it 'expands' by grace of import-replacing [my emphasis]. These two master economic processes are closely related, both being functions of city economics." ${ }^{46}$ Jacobs reminds us that most value chains are bootstrapped from within place-based middle market structure rather than continental market structure.

Food innovation is a relatively young discipline in the food sciences requiring students to operate as designers in a learning environment emphasizing innovation, including marketing and packaging of their work. Adaptive reuse of the VAC carves courtyards into the existing windowless big box, creating new landscaped spaces and building entrances accompanied by roof monitors to illuminate interior spaces (Figs. 14-15). The design re-organizes the facility as three lofts adaptive to changing production processes for baking, fermentation/pickling/dry goods production, juicing, distillation, food-grade cosmetic production, and packaging. A "Public Loft" fronts downtown California Avenue for community events, exhibitions, TV productions, and product sales.

(Fig. 16.) A "Production Loft," the heart of the facility, accommodates product prototyping, processing, and packaging (VAC too must comply with the FSMA regulations and Current Good Manufacturing Practices for Manufacturing, Packing, or Holding Human Food). (Fig. 17) An "Administration Loft" on the mezzanine houses classrooms, conference space, and offices to support education programs. Lofts are flexible spaces, accommodating changing production flows tailored to prototyping requirements for each product. Successful products showing market potential will develop their business operations at the Whitmore Food Hub Complex two miles away. 


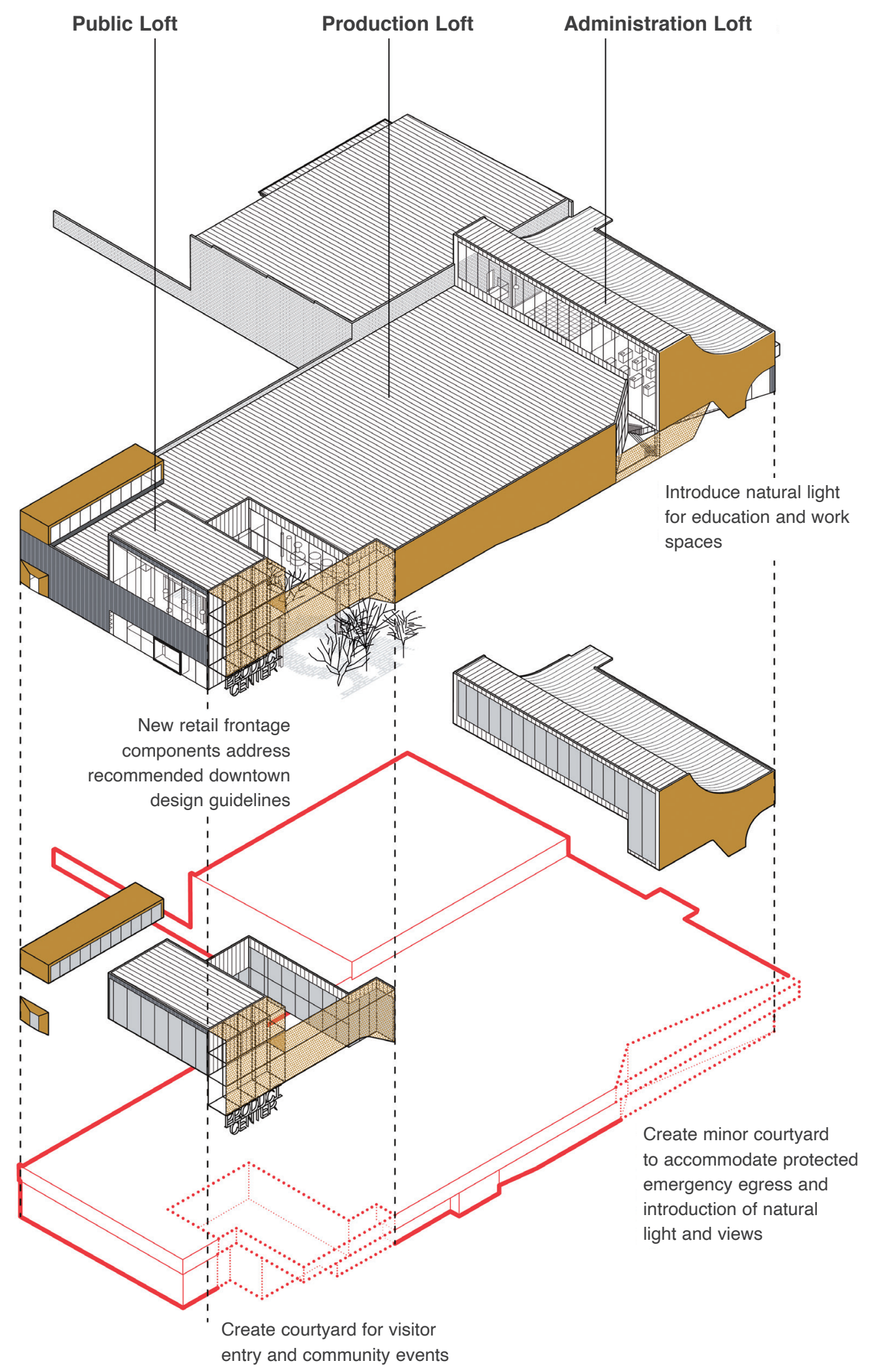

Figure 14. Retrofit of downtown warehouse as the Value-Added Product Development Center (VAC) - a food makerspace. 


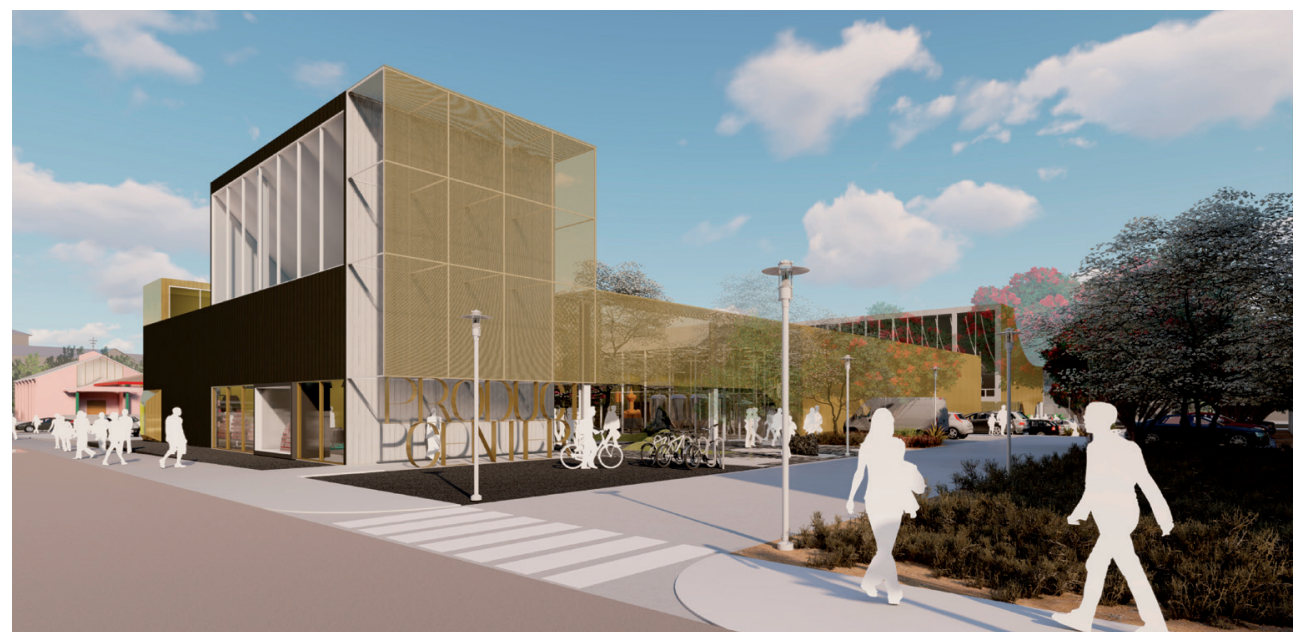

Figure 15. Street view of the VAC doubling as a production space and a community meeting space to celebrate food.

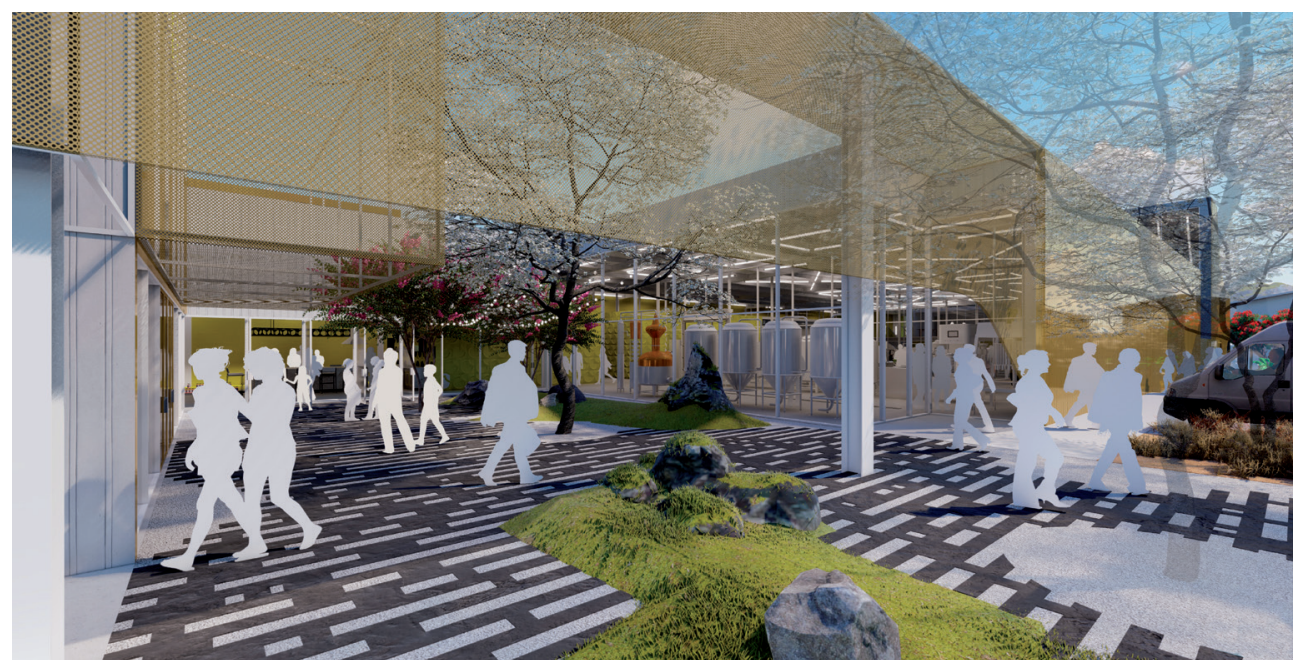

Figure 16. Entry courtyard to retail space and demonstration cooking kitchen.

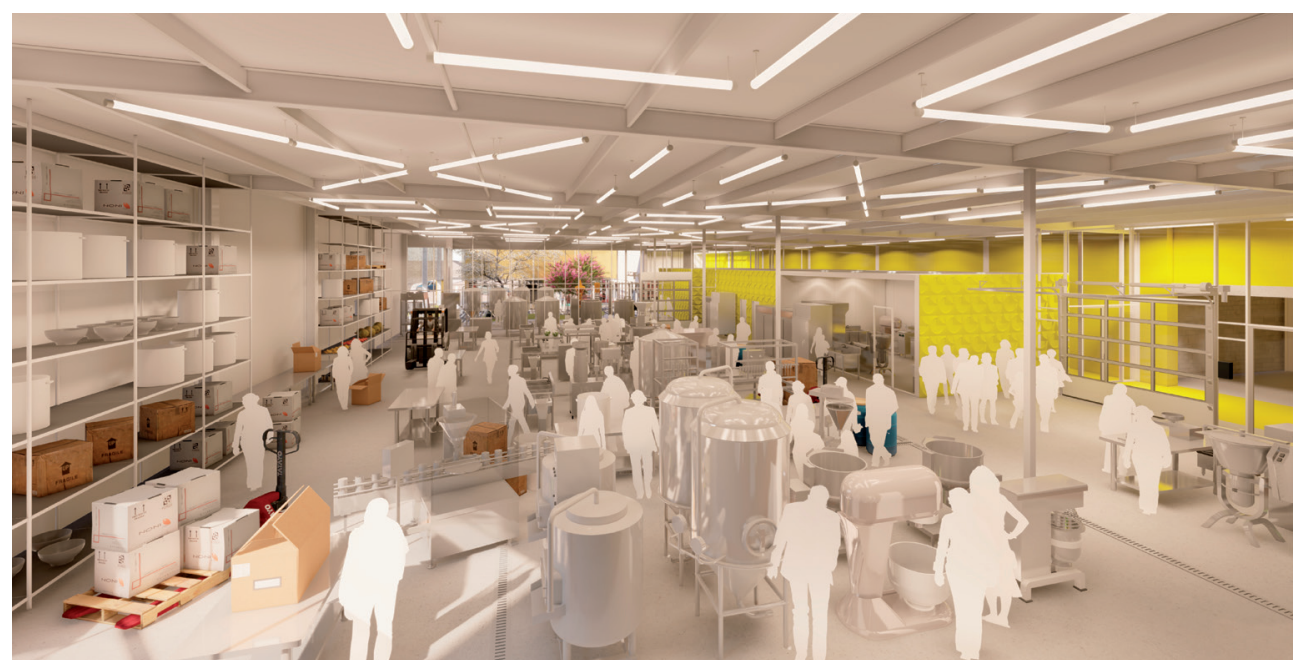

Figure 17. View looking into production loft with courtyard in the background. 
The food maker-space is an education policy statement: in the wake of monopoly market structure, food is being rethought as a commons open to a new ecosystem of actors. Education based on design thinking is reconfiguring food science, an academic discipline once dominated by a positivist linear mindset and often accused of enabling the commodification processes underwriting industrial agriculture. The repurposing of an off-campus warehouse to a hipster downtown makerspace doubles as a recruitment tool for attracting talent otherwise headed for enrollment in technology or design studies (Fig. 18).

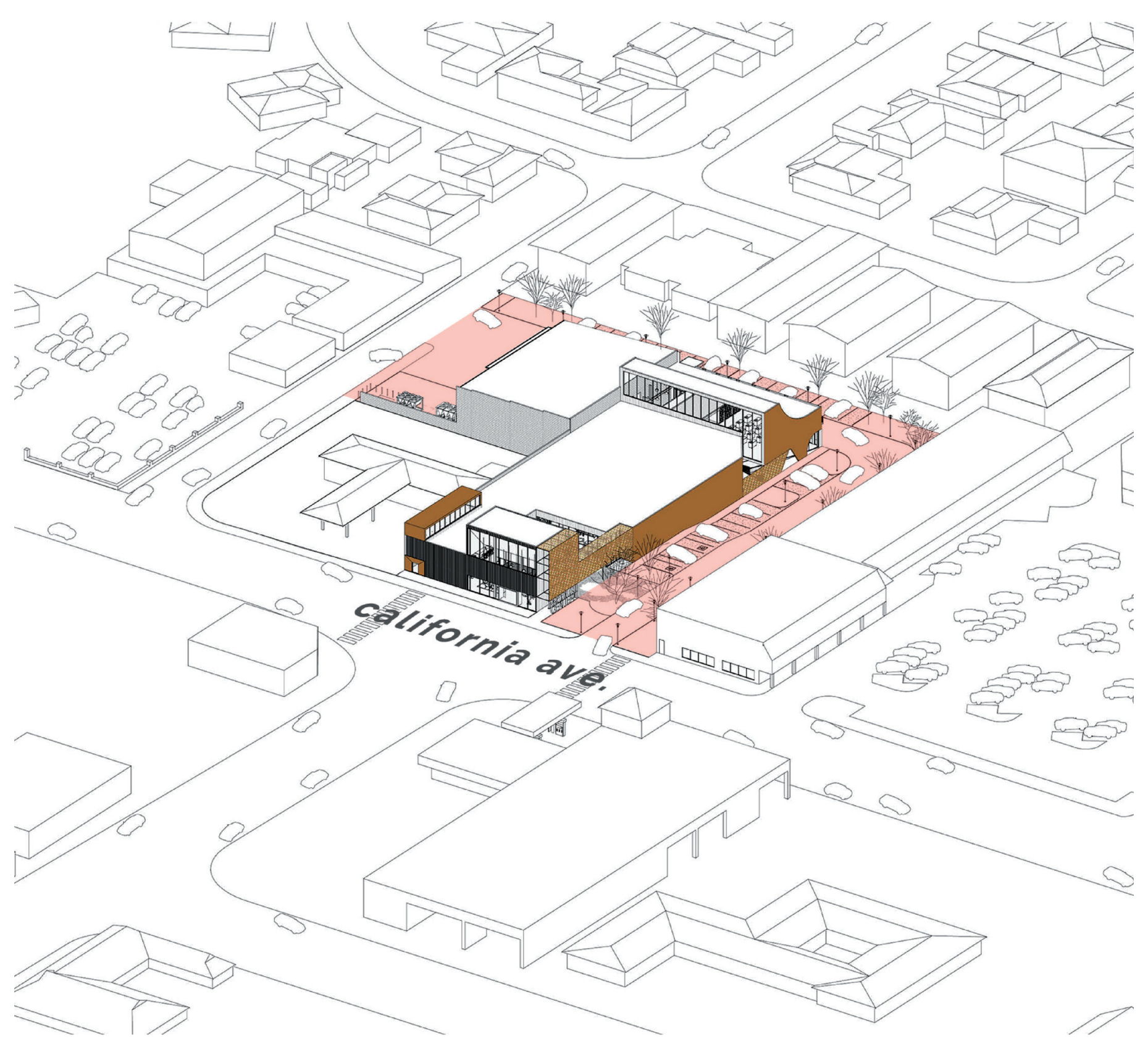

Figure 18. Axonometric of VAC on California Avenue, Wahiawa's main street. 


\section{FARM BASE YARD PROCESSING PROTOTYPES}

The FSMA regulations are comprehensive and also govern the design and operations of farm facilities. Off the record, agricultural officials predict that compliance costs will force 30 percent of Hawaiian farmers out of business. Many farms in Hawaii do not adhere to point-of-harvest food safety standards. Their operations are informal, ill-equipped financially and operationally to meet the FSMA mandates for climate control and refrigeration in processing facilities, strict separation of animals, products, visitors, and processes, as well as adoption of health and hygiene procedures in product handling, including water quality assurances.

The planning team prepared a base yard manual to illustrate post-harvest center prototypes for farms without access to commercial packaging and processing facilities. Only a few post-harvest activities are allowed under the FSMA Produce Rule, including drying/dehydrating, labeling, packaging, and treating (with ethylene) to manipulate ripening. All other post-harvest activities such as baking, boiling, bottling, canning, cooking, cooling, cutting, distilling, evaporating, eviscerating, juice extracting, formulating, freezing, grinding, homogenizing, irradiating, milling, mixing, pasteurizing, peeling, rendering, trimming, and waxing will make the facility subject to the more stringent FSMA Hazard Analysis and Risk-Based Preventive Controls Rule (the Facility Rule). The purpose of the base yard manual is to educate and instruct farmers on compliance with the Produce Rule, the minimum threshold in preparing products for market.

The base yard kit-of-parts and assembly protocols assist remote farmers in becoming compliant, adaptable, and profitable through scalable food processing functions, including expansion into profitable value-added enterprises like ecotourism (Fig. 19). Farmers may tailor their packaging and processing options to crop type and scale, off-grid capabilities, and changing levels of service over time (Fig. 20). The manual's menu of options and decision matrix walks farmers through the FSMA compliance requirements matched to planning for future change. The menu options entail a series of prefabricated concepts that, once assembled, create an FSMA-compliant, flexible, and unique post-harvest processing facility.

Design is premised on the wide availability of low-cost metal shipping containers as modular building blocks in combination with inexpensive perimeter fencing, light-weight open metal frame canopies, photovoltaic arrays, and water storage bladders. Since processing systems will be built without professional construction crews, base yard systems reflect an appropriate technology gauged to DIY skillsets and design-build construction tolerances already exercised within farming enterprises. However, climate-controlled facilities with higher energy and potable water needs are a substantial upgrade for many farmers, so base yard planning should carefully scale to near-term needs with options for ready 


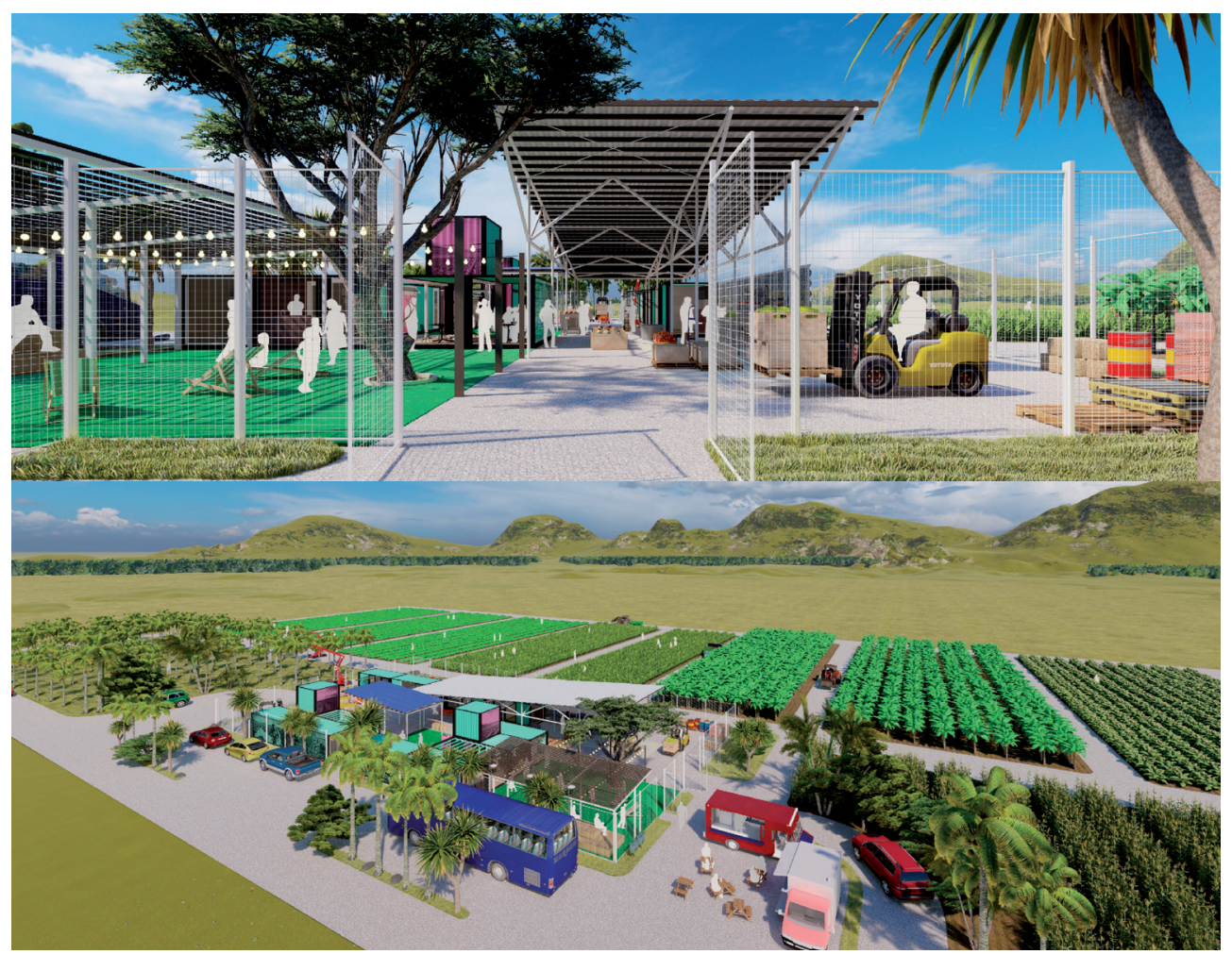

Figure 19. Prototypical base yard post-harvest processing center for farms without access to commercial processing facilities.

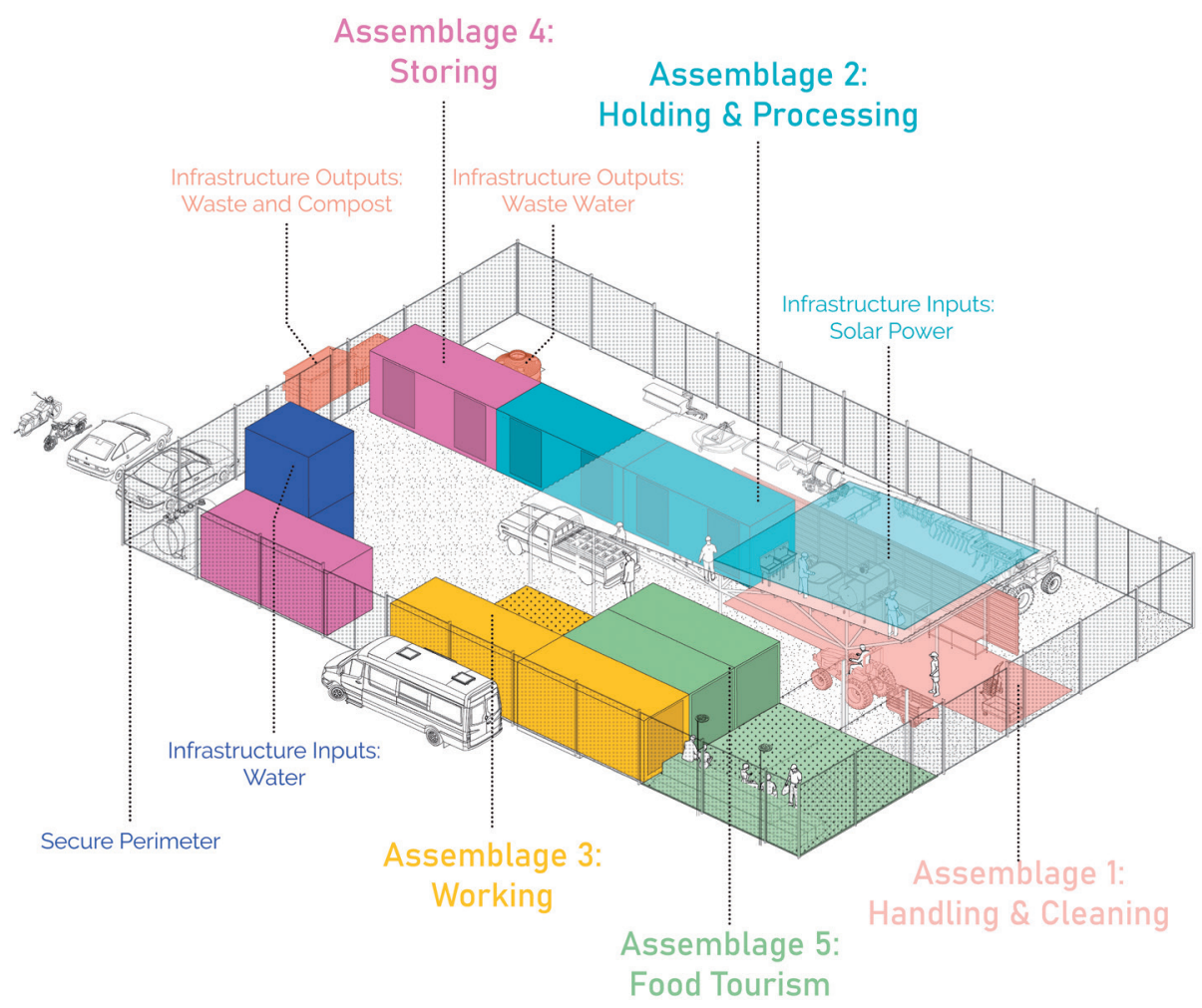

Figure 20. Five assemblage systems for tailoring food processing to crop type and scale, off-grid capabilities, and changing levels of service over time. 
growth. The base yard design decision matrix provides five core spatial assemblages based on product handling functions requiring separation per the FSMA regulations:

(1) handling and cleaning,

(2) holding and processing,

(3) working,

(4) storing, and

(5) food tourism.

Spatial assemblages can be arranged through preset plan options responsive to various operations and management models. Akin to Lego's building blocks, the base yard anticipates disassembly and reconfiguration vertically and horizontally as needs change. The pragmatism in complying with the FSMA processing regulations presents an opportunity to extend the farm's public face through gate sales and ecocultural learning experiences. Farm tours and customer-pick produce operations exemplify ways independent farmers can monetize non-agricultural services; important since the base operational costs of most farms in Hawaii are supplemented by off-farm income.

What is clear from the three projects (the food hub complex, the VAC, and the base yard prototype) is that middle market structure must be a continuous social learning system to sustain viability. Strategic partnerships among farmers, the state, higher education, civic groups, and commercial interests can create a commons symmetrical in its impacts to monopoly food systems. But can a food commons of short supply chains be sustained in the shadow of a dominant oligarchic commercial structure whose performance in some respects is unparalleled?

\section{CAN FOOD SUPPLY CHAINS SUPPORT MARKET OBJECTIVES AND SOCIAL VALUES CONCURRENTLY?}

Prevailing neoclassical economics holds that markets are built from rational actors working in their self-interests to maximize economic utility unburdened by noneconomic values. Can food supply chains, then, really deliver public goods (e.g., resiliency, security, access, sovereignty, fair trade, environmental stewardship, etc.) alongside economic benefits? For guidance, consider one of the largest alternative food supply networks, the only wholesale operations left in Manhattan that profitably delivers highquality, nutritious, fresh, diversified (even exotic despite no price premium) food products provided in abundance by a global network of independent mostly small farmers for middle-to-low-income consumers, yet not part of a "local" food movement (Chinatown). In her compelling book on this continental-scaled food network, From Farm to Canal Street (2015), economic botanist Valerie Imbruce shows how Chinatown's distributed supply chain differs from monopoly retailer-controlled supply in three ways. 
... (1) Enterprises from farm to retail level are decentralized, established by newcomers to the industry, and are often family owned and operated; (2) trade networks and businesses are established through ethnicity and kinship; and (3) cropping systems are diverse in cultivated plant species and management practices. ${ }^{47}$

More than an ethnic enclave (not all farmers and trade businesses are Asian), the Chinatown food network is transnational, aggregating over 200 specialized fruits and vegetables from across North America and as far south as Central America, with market distribution stretching beyond New York up and down the East Coast. ${ }^{48}$ While the Chinatown market is wholesaler-controlled, the key to its success lies in the proximity between embedded wholesalers and more than eighty core retail businesses in Lower Manhattan. Chinatown wholesalers extend those social ties to remote farmers, shippers, and network trade businesses nationwide. ${ }^{49}$ Network relationships built on trust are collaborative and even mentoring (involving information exchange and start-up assistance), unlike the asymmetric power relationships between monopoly food companies and their contract growers.

The Chinatown food network favors small farmers, including many immigrants in sub-tropical Florida and Central America growing a small Asian "home garden" characterized by permaculture techniques mixing perennials and annual crops in high-yield small-batch production. ${ }^{50}$ In this democratic food system healthy food is affordable and abundant; farmers enjoy higher returns; and noneconomic values lubricate its middle market structure. For some crops, like baby bok choy, farmers receive 20-33 percent of the retail price ${ }^{51}$ (in an industry where farmers count on 15 percent). The supply chain is modulated, inherently flexible, and has a broad base of suppliers with diversified products to satisfy multiple markets (including a creative food retail economy in Manhattan that is affordable to consumers of all income groups). The Chinatown food network shows that profitable, healthy, robust, fair trade food supply chains indeed require social capital to build viable market structure. Shared values do not have to be elitist (i.e., through a local food movement often detached from market principles). Value as capital is far more productive when channeled through deep partnerships that connect markets with nonmarket principles. More than scale, market structure distinguishes the profile of food.

Direct-to-consumer sales is efficient, allowing farmers to keep 100 percent of revenues minimizing or eliminating the role of market intermediaries, but it is not resilient since it lacks market structure (networking, learning, and redundancy). Direct sales to restaurants, grocers, schools, and retail venues allow some independent farmers to survive in a market otherwise sequestered by closed monopolistic structure. However, independent services sectors in shipping, processing, distribution, and marketing (services vertically integrated and privatized by monopolies) do not exist 
for independent farmers. This absence of support services disincentivizes farm start-ups whose rate is at an all-time low. In answering this, food hubs anchor a new type of wholesale food economy. They update the pluralistic middle market structure of the urban produce district and its economic and social web of diverse actors lost to the mid twentieth-century rationalization of wholesaling.

Food planning for Hawaii aims to build value chains beyond the traditional notion of the supply chain. Recall that value chains are networks based on cooperation, inclusivity, product and service differentiation, resilience, high levels of performance, shared vision and transparency in information sharing, shared decision-making, and the delivery of social and ecological value, in addition to economic value (the triple bottom line)..$^{52}$ Value chains leverage the comparative advantage of middle market structure, while offering little upside when market structure has been reduced to commodification processes that only maximize product volume and flow. When monopolistic structure as presently constructed fails to serve markets, in the myriad ways different people may define this, middle market structure offers alternative "foodways" to fulfill demand. Indeed, monopoly structure has pushed many farm start-ups toward organic farming models because, as agricultural sociologists Amy Guptill and Rick Welsh emphasize, "farming organically is not the alternative to farming conventionally but rather the alternative to not farming at all." 53 Downstream, resilient forms of direct sales coupled with the membershipbased cooperative groceries, and reemerging food hub districts (e.g., see the urban neighborhood growing around Detroit's Eastern Market) signals a return of food to the city and social life. Very different from their mid-century predecessors in the rationalization of food markets, architects and planners today have new kinds of roles to play in the reimagining of resource value chains beyond the design of buildings. 


\section{Notes}

1. Carolyn Steel, Hungry City: How Food Shapes Our Lives (London: Vintage, 2009), 307.

2. David Yaffee-Bellany and Michael Corkery, "Dumped Milk, Smashed Eggs, Plowed

Vegetables: Food Waste of the Pandemic," The New York Times, April 11, 2020,

https://www.nytimes.com/2020/04/11/business/coronavirus-destroying-food.html.

3. American Farm Bureau Federation, U.S. Food Expenditures at Home and Abroad, November 13, 2019, https://www.fb.org/market-intel/u.s.-food-expenditures-at-home-andabroad.

4. Fred Kirschenmann, G. W. Stevenson, Frederick Buttel, Thomas A. Lyson, and Mike Duffy, "Why Worry about the Agriculture of the Middle?," in Food and the Mid-Level Farm: Renewing an Agriculture of the Middle, eds. Thomas A. Lyson, G. W. Stevenson, and Rick Welsh (Cambridge MA, USA: The MIT Press, 2008), 3.

5. A dashboard profile of small farming shows that 88 percent of American farms are classified as small; only 41 percent turn an annual profit; and the average age of a beginner farmer is forty-seven. Yet small farmers account for 58 percent of the nation's direct-toconsumer sales. See Brian Barth, "By the Numbers: The State of Today's Independent Farmer," Modern Farmer, June 29, 2018, https://modernfarmer.com/2018/06/by-thenumbers-state-of-the-independent-farmer/.

6. Fred Kirschenmann et al., "Why Worry about the Agriculture," 3.

7. Helen Tangires, Movable Markets: Food Wholesaling in the Twentieth-Century City

(Baltimore: Johns Hopkins University Press, 2019), 9.

8. Ibid., 73.

9. Hedden quoted in Tangires, Movable Markets, 60.

10. Walter Page Hedden, How Great Cities are Fed (Boston: D. C. Heath \& Company, 1929).

11. Tangires, Movable Markets, 10.

12. Ibid., 84-92.

13. Contract growing is based on production contracts rather than market contracts where the grower is technically "handling the integrating firm's property and must follow the directives of the integrating firm." It is more a labor contract than one based on the exchange of goods, extending power asymmetries between large integrating firms and smaller growers, where the latter assume most of the risk and loses the autonomy of the traditional farmer. Contract growing significantly reduces agribusiness' transaction costs. See Mary Hendrickson, William Heffernan, David Lind, and Elizabeth Barham, "Contractual Integration in Agriculture: Is There a Bright Side for Agriculture of the Middle?," in Food and the MidLevel Farm: Renewing an Agriculture of the Middle, eds. Thomas A. Lyson, et al., 83. 14. David S. Johnson, John M. Rogers, and Lucilla Tan, "A Century of Family Budgets in the United States," Monthly Labor Review, May 2001, 33, https://www.bls.gov/opub/mlr/2001/05/ art3full.pdf.

15. American Farm Bureau Federation, U.S. Food Expenditures.

16. "The case for specialization is perhaps nowhere stronger than in agriculture, where the costs of production depend on natural resource endowments, such as temperature, rainfall, and sunlight, as well as soil quality, pest infestations, and land costs." Steve Sexton, "The Inefficiency of Local Food," Freakanomics, November 14, 2011, https://freakonomics. com/2011/11/14/the-inefficiency-of-local-food/.

17. Alexander Donofrio, "Feeding the City," Gastronomica 7, no. 4 (Berkeley CA, USA: University of California Press: Fall 2007): 35, doi:10.1525/gfc.2007.7.4.30.

18. The New York City Council, "FoodWorks: A Vision to Improve NYC's Food System," 2010, 44, cited in Nevin Cohen, "How Great Cities are Fed Revisited: Ten Municipal Policies to Support the New York City Foodshed," Fordham Environmental Law Review 22, no. 3 (2010): 701.

19. Pierre Bélanger, Landscape as Infrastructure: A Base Primer (Abingdon-on-Thames, UK: Routledge, 2017), 305.

20. Ibid., 301.

21. Ibid., 316.

22. Martin C. Heller and Gregory A. Keoleian, Life Cycle-Based Sustainability Indicators for Assessment of the U.S. Food System (Ann Arbor MI, USA: University of Michigan Center for Sustainable Systems, 2000), 42. 
23. Tom Philpot, Perilous Bounty: The Looming Collapse of American Farming and How We Can Prevent It (New York: Bloomsbury Publishing, 2020).

24. Ibid., 4.

25. Ibid., 75-76.

26. Ibid., 6.

27. Dan Walters, "Key Conflicts Roil California's Ever-Evolving Waterscape," CalMatters,

May 15, 2019, https://calmatters.org/environment/2019/05/future-of-california-water-supply/.

28. Philpot, Perilous Bounty, 93.

29. Ibid., 6.

30. Healthy ecosystems deliver seventeen life-affirming resources and processes known as ecological services, serving all living organisms. The seventeen services are grouped into four categories: "Provisioning Services" related to food, fiber, and fuel; "Regulating Services" supportive of climate regulation, and soil and water protection; "Supporting Services" affecting soil structure, water recycling, and genetic stores; and "Cultural Services." See Marty Matlock and Robert Morgan, Ecological Engineering Design: Restoring and Conserving Ecosystems Services (Hoboken NJ, USA: John Wiley \& Sons, Inc, 2011), 264. 31. Ed Maixner, "Farmers Markets and SNAP Redemption Boosting Local Food Sales," Agri-Pulse, July 31, 2019, https://www.agri-pulse.com/articles/12430-farmer-direct-saleskeeps-growth-on-several-paths.

32. Hawaii listed at number eight among the fifty states on the 2015 Locavore Index, a ranking of commitment to local foods. AJ Hughes, "Why Does Hawaii Import Most of Its Food Yet Rank High on Locavore Index?," Seedstock, August 17, 2015, http://seedstock. com/2015/08/17/why-does-hawaii-import-most-of-its-food-yet-rank-high-on-locavore-index/. 33. Wyatt Bechtel, "Shipping Cattle to the Mainland," Drovers, December 6, 2014, https://dy604qses7th.cloudfront.net/news/shipping-cattle-mainland.

34. USDA defines a small farm as an operation grossing less than $\$ 250,000$ annually in farm income. https://www.nass.usda.gov/Publications/AgCensus/2017/Online_Resources/ County_Profiles/Hawaii/cp99015.pdf.

35. State of Hawaii Department of Agriculture, 2017 Agriculture Census Showed Increase In Number of Farms but Lower Market Value, April 11, 2019, http://hdoa.hawaii.gov/blog/main/ nr19-09agcensus/.

36. James Barham et al., "Regional Food Hub Resource Guide," U.S. Department of Agriculture, Agricultural Marketing Service, April 2012, doi:10.9752/MS046.04-2012. 37. Estimates quoted from USDA's Economic Research Service report cited by the National Sustainable Agriculture Coalition, August 31, 2018, https://sustainableagriculture.net/blog/ fsma-compliance-costs/.

38. Food hub business models typically follow one of three market channels: Farm-tobusiness/institution, Farm-to-consumer such as CSA (Consumer-Supported Agriculture), or a hybrid. See James Barham et al., Regional Food Hub Resource Guide, 7.

39. Ibid., 8.

40. Ibid., 4 .

41. In contrast to traditional supply chains, value chains are "long-term networks of partnering business enterprises working together to maximize value from the partners and end customers of a particular product or service." Value chains feature cooperation, complex and differentiated products, balance between cooperation and competition, adaptation, shared vision and sharing of information, transparency and high levels of trust, and shared decision-making. See G. W. Stevenson and Rich Pirog, "Values-Based Supply Chains: Strategies for Agrifood Enterprises of the Middle," in Food and the Mid-Level Farm: Renewing an Agriculture of the Middle, eds. Thomas A. Lyson et al., 120.

42. James Barham et al., Regional Food Hub Resource Guide, 2.

43. Christina Page, Lionel Bony, and Laura Schewel, Island of Hawaii Whole System Project Phase I Report, Rocky Mountain Institute, March 2007, 45.

44. National Agricultural Statistics Service, Hawaii Agricultural Labor, United States Department of Agriculture, May 28, 2013, https://www.nass.usda.gov/Statistics_by_State/ Hawaii/Publications/Miscellaneous/aglaborFF.pdf. 45. Department of Numbers, Hawaii Household Income, 2015, http://www.deptofnumbers. com/income/hawaii/. 46. Jane Jacobs, Cities and the Wealth of Nations: Principles of Economic Life (New York: Random House, 1984), 39. 
47. Valerie Imbruce, From Farm to Canal Street: Chinatown's Alternative Food Network in the Global Marketplace (Ithaca NY: Cornell University Press, 2015), 12.

48. Ibid., 148.

49. Ibid., 145.

50. Ibid., 73-74.

51. Oscar Perry Abello, "Why Chinatown Is So Delicious, and Why It Might Not Be So Forever," Next City, May 16, 2019, https://nextcity.org/daily/entry/why-chinatown-is-sodelicious-and-why-it-might-not-be-so-forever.

52. Stevenson and Pirog, "Values-Based Supply Chains."

53. Amy Guptill and Rick Welsh, "Is Relationship Marketing an Alternative to the Corporatization of Organics? A Case Study of OFARM," in Food and the Mid-Level Farm: Renewing an Agriculture of the Middle, eds. Thomas A. Lyson et al., 61.

\section{Acknowledgments}

Many thanks to the reviewers for your time, insightful observations, and constructive suggestions. You helped me to reshape a far better argument.

Research, Planning and Design by the University of Arkansas Community Design Center and the University of Arkansas Resiliency Center, and the Fay Jones School of Architecture and Design, Department of Architecture, and Department of Landscape Architecture: Stephen Luoni, Francisco Mejias Villatoro, Michela Cupello, Claude M. Terral III, Garrett Grelle, Colby Leding, Raheel Ahmad, Jonathan Martinez, Kay Curry, Kenneth C. Hiley, Ethan G. Kaplan, Victor Lorenzo, Maranda Gerga, Brian Hernandez-Dimas, Austin Autrey, Caitlin Caum, Chelsea Garrison, Derek Hukill, William Pendleton, Joshua Powell, and Rafael Segura; plus Dr. Marty Matlock, Eric Cummings, Eric Boles, Deanna Mantooth-Hendrix, Kristina Ala-Kokko, Brittany Jurgens Gothard, Brandon Wayerski, Olivia Morgan, and Sam Lahodny; and Ken McCown, Anna Gwaltney, Alexander Holyfield, Alexis Pacheco, and Addison Warren.

The Architecture Firm of Record for the VAC is Urban Works Architecture: Lorrin Matsunaga, Vu Le, and James Noh. These projects were supported by Senator Donovan Dela Cruz, Hawaii State Legislature Senate District 22, Jimmy Nakatani, Executive Director, Hawaii Department of Agriculture, Agribusiness Development Corporation, and Todd Low, Manager, Hawaii Department of Agriculture Aquaculture and Livestock Support.

Consultants: University of Arkansas Food Innovation Center, Brightwater: A Center for the Study of Food, High Technology and Development Corporation, Hawaii Housing Finance Development Corporation, Mari's Gardens, University of Hawaii Community Colleges, University of Hawaii Maui College, University of Hawaii at Manoa, School of Architecture, and University of Hawaii Community Design Center.

Project fees to the University of Arkansas Community Design Center and the University of Arkansas Resiliency Center were provided by the client, the Hawaii Department of Agriculture. Publication funding was provided by the University of Arkansas at Fayetteville and the UA Community Design Center.

\section{Credits}

Figure 1: photo by @ David K. O’Neil

Figures 2-20: images @ University of Arkansas Community Design Center. 
Stephen Luoni is the Director of the University of Arkansas Community Design Center (UACDC) where he is the Steven L. Anderson Chair in Architecture and Urban Studies and a Distinguished Professor of Architecture. Under his direction since 2003, UACDC's design and research have won more than 180 awards, all for urban design, research, and education. Luoni's work specializes in interdisciplinary public-interest projects combining landscape, urban, ecological engineering, and architectural design. E-mail: sluoni@uark.edu 